\title{
An Integrated Approach for Hemicellulose Extraction from Forest Residue
}

\author{
Debjani Ghosh, ${ }^{\mathrm{a}}$ Joanne Tanner, ${ }^{\mathrm{b}}$ Jean-Michel Lavoie, ${ }^{\mathrm{c}}$ Gil Garnier, ${ }^{\mathrm{b}, *}$ and \\ Antonio F. Patti ${ }^{\text {a, } *}$
}

\begin{abstract}
An alkali-mediated hydrothermal approach was optimized for partial extraction of high-purity hemicellulose (xylan) from a timber waste product (unbleached eucalyptus sawdust). The extraction process was: a) extractives removal using sequential solvent extraction; b) alkali-mediated hydrothermal extraction of hemicellulose; and c) purification of the isolated hemicellulose fraction. Biomass was extracted in an autoclave at a fixed temperature of $121^{\circ} \mathrm{C}$ while varying the extraction time ( $1 \mathrm{~h}$ to $\left.2.5 \mathrm{~h}\right)$ and alkali concentration $(10 \%, 15 \%$, and $20 \% \mathrm{w} / \mathrm{v})$. Using this simple approach, high purity polymeric hemicellulose with molecular mass (21 to $30 \mathrm{kDa}$ ) was recovered in yields of 35 to $37 \%$. The isolated hemicellulose can be chemically transformed into high-value commercial products such as prebiotics (xylooligosaccharides), surfactants, hydrogels, and food packaging materials. The purified residue can be utilized in existing kraft pulping processes. The integration of hemicellulose extraction into existing pulping process represents additional valorization of timber resources.
\end{abstract}

Keywords: Eucalyptus sawdust; Alkali treatment; Xylan; Purification; Xylanase; Xylooligosaccharide

Contact information: a: School of Chemistry, Monash University, Clayton, VIC, 3800, Australia; b: Department of Chemical Engineering, Bioresource Processing Research Institute of Australia, Monash University, Clayton, VIC, 3800, Australia; c: Industrial Research Chair on Cellulosic Ethanol and Biocommodities (CRIEC-B), Département de Génie Chimique et de Génie Biotechnologique, Université de Sherbrooke, Québec, Canada; *Corresponding authors: tony.patti@monash.edu; gil.garnier@monash.edu

\section{INTRODUCTION}

There is a need to diversify the use of biomass beyond the traditional applications (fuelwood, animal feedstock, and paper). At the same time, society's current dependence on limited fossil fuel resources must be reduced (Warden and Haritos 2008). Crosscategory applications and upgrading of low-value biomass have the potential to enable kraft pulping facilities to evolve into biorefineries of the future with long-term sustainability and economic viability (Castaldi et al. 2017). The extraction of pulp byproducts, such as hemicellulose and lignin, are viable and easily integrated processes because the pulp mills are already equipped with the required infrastructure, logistics, and know-how for processing large amounts of lignocellulosic materials. However, to succeed in transforming a classical model to a more sustainable one, issues related to the recovery and balance between quantities and qualities of biomass components need to be addressed.

Hemicellulose is one of the major biomass components along with cellulose and lignin. Depending on the biomass source, hemicellulose composition can range from 20 to $35 \%$ by dry mass in woods and other plants (Rowell 2012). Hemicellulose is already an important source of commercially produced high-valued chemicals including xylose and xylitol (Naqvi and Yan 2015). Chemical modification can additionally be used to transform crude hemicellulose into specialty products, such as nutritional supplements, green 
packaging materials, emulsifiers, encapsulating agents, and adhesive components, many of which are considered to have high potential for future commercialization (Rafiqul and Sakinah 2013; Naidu et al. 2018). Recent literature reports evidence of hemicellulosederived sugars as potential prebiotics (Aachary and Prapulla 2011). However, utilization of hemicellulose is severely limited by its unavailability in large quantities. Thus, a simple and robust extraction strategy is required for optimal recovery of this abundant and potentially valuable biomass component.

Woody biomasses are naturally recalcitrant, due to their strong lignin-carbohydrate complexes; hence, fractionation of biomass constituents is a known challenge (Bhutto et al. 2017). The literature reports different approaches for hemicellulose recovery from a variety of raw materials. Alkali solubilization of hemicellulose is the more mature and widely used extraction strategy for obtaining high molar mass hemicellulose (Table 1). The common alkali types used for extraction are $\mathrm{KOH}$ (potassium hydroxide) and $\mathrm{NaOH}$ (sodium hydroxide) (Kim et al. 2016). Alkali reagents can selectively dissolve the ester linkages between hemicellulose and lignin, leaving cellulose largely unaltered; this is a key advantage of this process (Farhat et al. 2017). Furthermore, most of the acetyl groups are lost from the hemicellulose polymer chain during the alkali extraction due to deesterification reactions (saponification). As a result, less branched or more uniform hemicellulose polymers are recovered. However, alkali reagents can solubilize lignin, potentially contaminating the hemicellulose and highlighting a compromise between achievable quality and quantity when using the alkali methods. One possible way to remove lignin from hemicellulose is through ethanol washing. Ethanol solubilizes most of the lignin that is initially co-extracted with the hemicellulose, resulting in a relatively purified hemicellulose precipitate. Lignin remaining in the ethanol fraction can be further utilized as fuel, or as a starting material to produce value-added products. Ethanol can be recovered and recycled to the neutralization process, and the solid biomass residue can be directly fed into the kraft digestion step. The residual biomass from alkali extraction is well suited for integration into the existing kraft pulping cycle, where the digestion step essentially uses white liquor, which is a treatment with sodium hydroxide and sodium sulfide. The isolated hemicellulose can be purified and used for further transformation in a biorefinery (Al-Dajani and Tschirner 2008; Vila et al. 2012; Hamaguchi et al. 2013; Johakimu and Andrew 2013; Shao et al. 2019).

During alkali extraction, the cellulose crystallinity is reduced, and more hemicellulose and lignin are dissolved into the extraction liquid. The effectiveness of alkali extraction can vary across feedstocks (Table 1), particularly those with high lignin content such as woody biomass. Consequently, de-lignified biomass, such as bleached wood pulp, is usually preferred as the starting material for hemicellulose extraction, wherein the contamination from lignin can be avoided. However, delignification methods can be timeconsuming and often use harsh chemicals that are not eco-friendly and can modify the native hemicellulose structure (Wu et al. 2019). There are numerous publications (Table 1) available on alkali extraction of hemicellulose from de-lignified biomass; however, direct hemicellulose extraction from unbleached or raw biomass is limited particularly from Australian-grown woody resource.

One potential untapped source of hemicellulose is raw wood sawdust, a by-product from existing pulp and paper mills. Annually, 5.49 million cubic meters of sawlog residue are generated in Australia, and approximately 29\% (by volume) of the sawmill produce is sawdust, which is predominantly burnt for energy or used for animal bedding in farms. 
Table 1. Alkali Extraction of Hemicellulose from Various Feedstocks

\begin{tabular}{|c|c|c|c|c|}
\hline Extraction Method & Feedstock & $\begin{array}{c}\text { Yield of } \\
\text { Hemicellulose }\end{array}$ & $\begin{array}{c}\text { Average } \\
\text { Molar Mass of } \\
\text { Hemicellulose }\end{array}$ & Study \\
\hline $\begin{array}{c}\text { Alkali extraction ( } 1.04 \\
\text { to } 2.08 \mathrm{M} \mathrm{NaOH}, 32 \text { to } \\
\left.90^{\circ} \mathrm{C} \text {, and } 4 \mathrm{~h}\right)\end{array}$ & Aspen chips & $5 \%$ & $\begin{array}{c}>21,030 \\
\mathrm{~g} / \mathrm{mol}\end{array}$ & $\begin{array}{l}\text { (Al-Dajani and } \\
\text { Tschirner 2008) }\end{array}$ \\
\hline $\begin{array}{c}\text { Alkali incubation (12\% } \\
\left.\mathrm{NaOH}, 50^{\circ} \mathrm{C} \text {, and } 3 \mathrm{~h}\right) \\
\text { with hydrothermal } \\
\text { treatment }\left(120^{\circ} \mathrm{C}, 45\right. \\
\text { min })\end{array}$ & Natural grass & $98 \%$ & Not reported & (Samanta et al. 2012) \\
\hline $\begin{array}{l}\text { Green liquor (mixture of } \\
\text { sodium sulphide, } \\
\text { sodium hydroxide, and } \\
\text { sodium carbonate) } \\
\text { incubation at } 170^{\circ} \mathrm{C} \text { for } \\
15 \text { to } 90 \mathrm{~min}\end{array}$ & $\begin{array}{l}\text { Eucalyptus } \\
\text { grandis } \\
\text { woodchips }\end{array}$ & $14 \%$ & Not reported & $\begin{array}{l}\text { (Johakimu and } \\
\text { Andrew 2013) }\end{array}$ \\
\hline $\begin{array}{c}\text { Ethanol-alkali } \\
\text { extraction }(70 \% \text { ethanol } \\
\text { solution with } 1 \% \mathrm{NaOH} \\
\text { w/v) with ultrasound } \\
\left(75^{\circ} \mathrm{C}, 3 \mathrm{~h}\right) \text { remaining } \\
\text { solid alkali extracted } \\
\left(8 \% \mathrm{NaOH} \text { w/v, } 40^{\circ} \mathrm{C},\right. \\
\text { and } 20 \mathrm{~h}) \\
\end{array}$ & $\begin{array}{l}\text { Hybrid poplar } \\
\text { wood } \\
\text { (delignified) }\end{array}$ & $34 \%$ and $50.4 \%$ & $\begin{array}{c}17,480 \text { and } \\
14,670 \mathrm{~g} / \mathrm{mol}\end{array}$ & (Jiang et al. 2014) \\
\hline $\begin{array}{c}\text { Alkali extraction (1.5 M } \\
\mathrm{NaOH}, 110^{\circ} \mathrm{C} \text {, and } 1 \\
\mathrm{~h})\end{array}$ & $\begin{array}{l}\text { Rapeseed } \\
\text { straw }\end{array}$ & $47 \%$ & $3 / 5,000 \mathrm{~g} / \mathrm{mol}$ & (Svärd et al. 2017) \\
\hline $\begin{array}{l}\text { Alkali incubation ( } 10 \% \\
\mathrm{NaOH} \text { w/v, } 65^{\circ} \mathrm{C} \text {, and } \\
8 \mathrm{~h}) \text { with hydrothermal } \\
\text { extraction }\left(121^{\circ} \mathrm{C}, 1 \mathrm{~h}\right)\end{array}$ & $\begin{array}{l}\text { Areca nut } \\
\text { husk }\end{array}$ & $94 \%$ & Not reported & (Singh et al. 2018) \\
\hline $\begin{array}{c}\text { Alkali extraction }(5 \% \\
\left.\mathrm{KOH}, 50^{\circ} \mathrm{C} \text {, and } 3 \mathrm{~h}\right) \\
\text { with ultrasound }(30 \\
\text { min) }\end{array}$ & $\begin{array}{l}\text { Eucalyptus } \\
\text { grandis } \\
\text { (delignified) }\end{array}$ & $95 \%$ & $\begin{array}{c}74,510 \text { to } \\
66,770 \mathrm{~g} / \mathrm{mol}\end{array}$ & (Xu et al. 2018) \\
\hline $\begin{array}{c}\text { Alkali extraction (5 to } \\
10 \% \mathrm{NaOH} \text { w/w, } 25^{\circ} \mathrm{C} \text {, } \\
1 \text { to } 2 \mathrm{~h} \text {, and } 120 \text { to } \\
1042 \mathrm{rpm})\end{array}$ & $\begin{array}{l}\text { Bleached } \\
\text { eucalyptus } \\
\text { kraft pulp }\end{array}$ & 43 to $97 \%$ & $\begin{array}{c}16,800 \text { to } \\
22,700 \mathrm{~g} / \mathrm{mol}\end{array}$ & $\begin{array}{c}\text { (Marques et al. } \\
\text { 2019) }\end{array}$ \\
\hline $\begin{array}{c}\text { Alkali with } \\
\text { hydrothermal extraction } \\
(0.25 \text { to } 0.75 \% \mathrm{NaOH} \\
\mathrm{w} / \mathrm{w}, 160^{\circ} \mathrm{C} \text {, and } 30 \\
\min )\end{array}$ & Reed scraps & 23.9 to $24.5 \%$ & $\begin{array}{c}2431 \text { to } 420 \\
\mathrm{~g} / \mathrm{mol}\end{array}$ & (Chen et al. 2019) \\
\hline $\begin{array}{c}\text { Alkali with } \\
\text { hydrothermal extraction } \\
\text { (7 to } 11 \% \mathrm{NaOH}, 60 \text { to } \\
80^{\circ} \mathrm{C} \text {, and } 3 \text { to } 5 \mathrm{~h} \text { ) } \\
\end{array}$ & $\begin{array}{c}\text { Poplar } \\
\text { powder } \\
\text { (delignified) }\end{array}$ & $52.8 \%$ & $23,380 \mathrm{~g} / \mathrm{mol}$ & (Shao et al. 2019) \\
\hline
\end{tabular}

*: Based on original amount of hemicellulose in the dry biomass 
A small amount may be used as a filler material in papermaking (Downham et al. 2019). Eucalyptus species are the primary source of fiber for the Australian domestic pulp and paper industry. Sawdust is typically a mixture of different wood species and ages of raw material (timber) accumulated in the sawmill. Furthermore, the cost of handling sawdust nullifies its value as a fuel, and its combustion is predominantly a convenient local means of disposal. As a result, sawdust is not only abundant but also a cheap source of biomass, which can be put to a better use with the application of new technologies. The other advantage of using sawdust as a feedstock for hemicellulose extraction is that it is already present as small particles with high surface area, making it ideal for liquid-solid processing.

This study reports the recovery of polymeric hemicellulose from raw, mixed eucalyptus sawdust generated in timber mills using an alkali mediated hydrothermal approach. Mixed eucalyptus sawdust was used as a substitute for wood chips to demonstrate the process to integrate hemicellulose extraction into the existing Australian pulp and paper mills. A range of alkali concentrations and extraction times was studied to determine the combined effect on hemicellulose extraction and depolymerization. Under the optimized conditions, it may be possible to achieve a sustainable production process for hemicellulose that can be directly integrated into existing kraft mills (Fig. 1). This research has the potential to facilitate process efficiency improvement, resource recovery, and may lead to an integrated forest biorefinery, wherein a by-product from a timber mill such as sawdust can be upgraded to a material of substantial value.

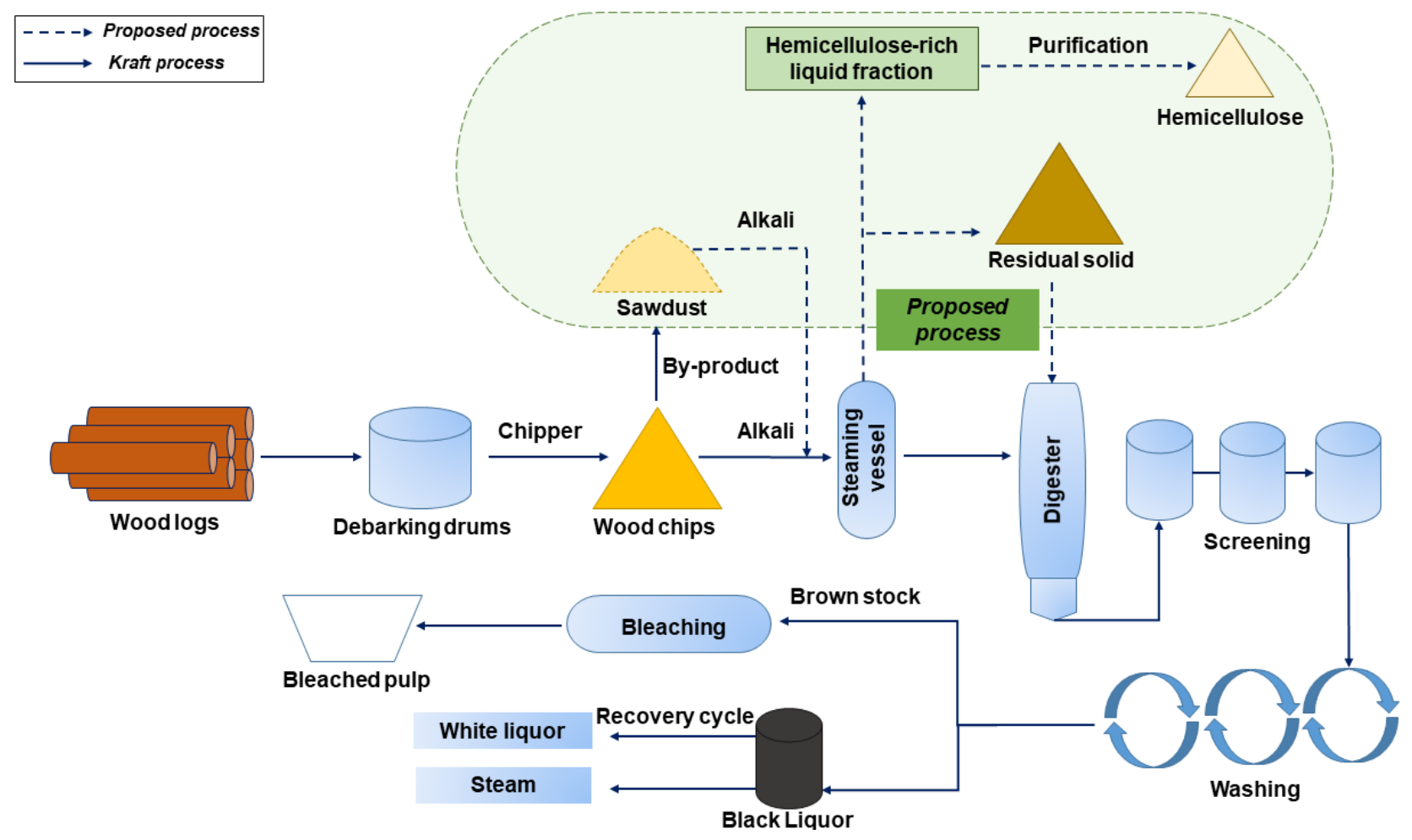

Fig. 1. Proposed process for extraction of hemicellulose (green) and integration to the kraft process (blue) 


\section{EXPERIMENTAL}

\section{Materials}

Eucalyptus sawdust was procured from a local sawmill based in Melbourne, Australia. Beechwood xylan and monosaccharide standards were obtained from SigmaAldrich (St. Louis, MO, USA). Xylanase from Thermomyces lanuginosus (2500 U/g) was procured from Sigma-Aldrich (St. Louis, MO, USA), xylooligosaccharide (XOS) standards were obtained from Megazyme (Chicago, IL, USA). All other chemicals were of analytical grade.

\section{Chemical Composition Analysis}

Extractives

The total extractives in the biomass were quantified following the standard NREL TP-510-42619 protocol (Sluiter et al. 2008). Prior to the study, the sawdust was sieved, and the fraction between 250 and $425 \mu \mathrm{m}$ (40 to 60 mesh) was utilized. The moisture content of the sawdust was $7 \% \pm 0.77 \%$ analyzed in triplicate. Oven-dried sawdust was sequentially extracted with ethanol $(95 \%)$ followed by distilled water. The measurements were carried out in triplicate.

\section{Ash content}

The total ash was determined as per the ASTM E1755-01 (2012) standard method. A known amount of previously sieved and oven-dried sawdust was heated at $575{ }^{\circ} \mathrm{C} \pm 25$ ${ }^{\circ} \mathrm{C}$ overnight under air. At the end of the heating cycle, samples were cooled in a desiccator before their final weights were recorded. The measurements were carried out in triplicate.

\section{Hemicellulose and $\alpha$-cellulose}

Hemicellulose and $\alpha$-cellulose contents were determined following the method described by Rowell (2012). Briefly, extractive-free sawdust was treated with sodium chlorite and acetic acid yielding lignin-free holocellulose (hemicellulose and $\alpha$-cellulose together). The alkali soluble fraction of holocellulose was used as a measure of hemicellulose content, while the remaining solid was considered as $\alpha$-cellulose. The measurements were carried out in triplicate.

\section{Lignin}

Extractive-free sawdust was digested with strong acid to dissolve the carbohydrates. The remaining insoluble part at the end of digestion was quantified as per the ASTM E1721-01 (2015) standard. The measurements were carried out in triplicate.

\section{Extraction of Hemicellulose} Removal of extractives

This step was taken to minimize the interference from the extractives in the subsequent process (Sluiter et al. 2008). Sawdust was sieved to a mesh size of 40 to 60 . The sieved sawdust was sequentially Soxhlet-extracted with ethanol (95\%) and water. The extractive-free sawdust obtained was oven-dried at $100{ }^{\circ} \mathrm{C}$ and stored prior to further experiments. 


\section{Extraction of hemicellulose}

For the extraction, $40 \mathrm{~g}$ of sodium hydroxide solution $(10 \%, 15 \%$, and $20 \% \mathrm{w} / \mathrm{v})$ was added to $4 \mathrm{~g}$ oven-dried extractive-free sawdust, maintaining a ratio of 10:1 (extraction liquid:biomass) in capped Schott Duran bottles at room temperature (without any prior incubation). Subsequently, the reaction vessels were autoclaved at a fixed temperature of $121{ }^{\circ} \mathrm{C}$ at $15 \mathrm{psi}(103.4 \mathrm{kPa})$ pressure for the desired extraction time $(1 \mathrm{~h}, 1.5 \mathrm{~h}, 2 \mathrm{~h}$, and $2.5 \mathrm{~h})$. Each extraction was carried out in triplicate.

The reaction vessels were cooled, and the mixture filtered under vacuum using a Buchner funnel. The solid residue was washed with hot deionized water (two times the volume of extraction liquid). The washed (alkali-free) solid residue was oven-dried at 100 ${ }^{\circ} \mathrm{C}$, and its chemical composition (cellulose, hemicellulose, and lignin) was determined using the methods as mentioned in the section 'Chemical Composition Analysis'.

The total filtrate from the reaction was slowly acidified to $\mathrm{pH} 5$ to 5.5 using glacial acetic acid under constant stirring (300 rpm) in a water bath at $25^{\circ} \mathrm{C}$. Hemicellulose was precipitated from the neutralized filtrate with ice-cold $95 \%$ ethanol (three times the volume of neutralized filtrate). To ensure complete precipitation, the suspension was left overnight at low temperature $\left(10^{\circ} \mathrm{C}\right)$ prior to purification.

\section{Purification of crude hemicellulose}

The crude hemicellulose precipitate obtained above as mentioned in previous section was centrifuged (4500 rpm, $15 \mathrm{~min}$ ) and the supernatant was decanted. This was followed by washing with distilled water $(30 \mathrm{~mL})$ in centrifuge tubes. Washing was continued until the colour of supernatant changed from dark brown to colourless. Between each repeated washing step, the supernatant was filtered, and the conductivity measured using a conductivity meter (SenSion, HACH, Loveland, CO, USA). Once the conductivity was below $10 \mu \mathrm{S}$ and stable, the precipitate was further dialyzed (3.5k Da cut off, Snakeskin Dialysis Tubing; Thermo Scientific, Rockford, IL, USA) against deionized water for three days to remove dissolved salts, and then freeze-dried. The freeze-dried hemicellulose solid was pulverized (mortar and pestle) and stored in closed test tubes for further analysis. The overall process for hemicellulose extraction is summarized in Fig. S1.

\section{Yield of the isolated hemicellulose}

The yield of the isolated hemicellulose was obtained based on the on the specific yield and total yield using Eqs. 1 and 2:

$$
\begin{aligned}
& \text { Specific yield }(\%)=\frac{\text { Weight of freeze-dried hemicellulose }(\mathrm{g})}{\text { Total hemicellulose available in biomass }(\mathrm{g})} \times 100 \% \\
& \text { Total yield }(\%)=\frac{\text { Weight of freeze-dried hemicellulose }(\mathrm{g})}{\text { Total dry weight of biomass }(\mathrm{g})} \times 100 \%
\end{aligned}
$$

\section{Characterization of the Isolated Hemicellulose}

\section{FTIR analysis}

An Agilent Cary 630 FTIR (Agilent Technologies, Santa Clara, CA, USA) was used to study the functional groups of the isolated hemicellulose. The IR spectra were recorded over a range of 400 to $4000 \mathrm{~cm}^{-1}$ with a resolution of $4 \mathrm{~cm}^{-1}$. The spectrum for the purchased beechwood xylan (> 90\% xylan residue, Sigma-Aldrich, St. Louis, MO, USA) was used for comparison to determine the xylan characteristic peaks. 


\section{Solid state ${ }^{13} \mathrm{C}-\mathrm{NMR}$}

Solid-state carbon-13 $\left({ }^{13} \mathrm{C}\right)$ nuclear magnetic resonance (NMR) spectra of isolated hemicellulose and purchased beechwood xylan were obtained on a Bruker Avance spectrometer (Karlsruhe, Germany) equipped with a 7.05 Tesla magnet, operating at 75.4 $\mathrm{MHz}$ for ${ }^{13} \mathrm{C}$, using $4 \mathrm{~mm}$ outside diameter (O.D.) rotors, and a magic-angle spinning (MAS) rate of $10 \mathrm{kHz}$. For the ${ }^{13} \mathrm{C}$ cross-polarization magic angle spinning (CP/MAS), the pulse program cp.av and continuous wave $(\mathrm{CW})$ proton decoupling were employed. The 24000 transients were acquired using a contact time of $2 \mathrm{~ms}$, an acquisition time of $20 \mathrm{~ms}$ (1992 data points), and a recycle delay of $4 \mathrm{~s}$.

\section{Thermogravimetric analysis (TGA)}

A Mettler TGA/DSC1 STAR (Mettler-Toledo Ltd., Columbus, OH, USA) was used for TGA. Isolated hemicellulose samples (1 to $10 \mathrm{mg}$ ) were heated in alumina pans from 25 to $800{ }^{\circ} \mathrm{C}$ at a heating rate of $10^{\circ} \mathrm{C} \mathrm{min}^{-1}$ with a nitrogen flow rate of $50 \mathrm{~mL} \mathrm{~min}{ }^{-1}$. Once the temperature reached $800{ }^{\circ} \mathrm{C}$, the atmosphere was changed to air, maintaining the flow rate at $50 \mathrm{~mL} \mathrm{~min}^{-1}$.

\section{Molecular weight analysis by size exclusion chromatography}

Size exclusion chromatography (SEC) was performed using a Tosoh High Performance EcoSEC HLC-8320GPC system (Tosoh Corporation, Shunan, Yamaguchi, Japan) coupled with a refractive index detector (RID) (Tosoh Corporation, Shunan, Yamaguchi, Japan) and a UV detector $(280 \mathrm{~nm})$ (Tosoh Corporation, Shunan, Yamaguchi, Japan). The TSKgel SuperH-RC was set as the reference column, and three TSKgel PWXL analytical columns (TSKgel G5000PWxL, TSKgel G6000PWxL, and TSKgel MPWxL) were connected in series. The system was calibrated with a series of dextran standards ranging from 5 to $110 \mathrm{k} \mathrm{Da}$. The column temperature was maintained at $40{ }^{\circ} \mathrm{C}$. The mobile phase was $0.1 \mathrm{M} \mathrm{NaNO}_{3}$ (sodium nitrate) and $0.1 \mathrm{M} \mathrm{NaHCO}_{3}$ (sodium bicarbonate), $(\mathrm{pH}$ $\sim 8.3$ ) in deionized water at a flow rate of $1.0 \mathrm{~mL} \mathrm{~min}^{-1}$. For analysis, freeze-dried hemicellulose samples were dissolved in the mobile phase $(3 \mathrm{mg} / 3 \mathrm{~mL})$ at room temperature and filtered using $0.45 \mu \mathrm{m}$ nylon membranes. Lastly, $100 \mu \mathrm{L}$ of the filtered samples were injected into the SEC system.

\section{Chemical composition of hemicellulose}

The sugar composition of the isolated hemicellulose was determined by adopting the standard acid hydrolysis protocol from the NREL Laboratory Analytical Procedures (Raymond and Tina 1996). In this two-step process, hemicellulose was hydrolyzed to its constituent monomers by reaction with $72 \%$ sulfuric acid for $1 \mathrm{~h}$ at $30{ }^{\circ} \mathrm{C}$ followed immediately by reaction with $4 \%$ sulfuric acid at $121{ }^{\circ} \mathrm{C}$ for $1 \mathrm{~h}$. The sample was neutralized to $\mathrm{pH} 5$ using calcium carbonate, centrifuged, and the clear supernatant was syringe filtered for monosaccharide analysis by liquid chromatography (LC).

The LC was performed using an Agilent Infinity 1290 system (Agilent Technologies, Santa Clara, CA, USA) coupled with a refractive index detector (RID) and a UV detector set at $280 \mathrm{~nm}$. An Agilent HiPlex-H column $(300$ x $7.7 \mathrm{~mm}$, Agilent Technologies, Santa Clara, CA, USA) was used for the sugar composition analysis. The column was operated at $65{ }^{\circ} \mathrm{C}$ with acidified deionized water $(5 \mathrm{mM}$ sulfuric acid) at a

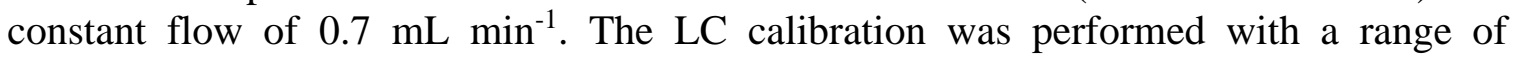
monomeric and oligomeric sugars (xylose, glucose, arabinose, xylobiose, and xylotriose), glucuronic acid, and acetic acid. The measurements were carried out in triplicate. 


\section{Solubility of the Isolated Eucalyptus Hemicellulose}

To study the solubility of the isolated hemicellulose, $20 \mathrm{mg}$ of the sample was mixed with $10 \mathrm{~mL}$ of solvent and stirred overnight at $300 \mathrm{rpm}$. A range of solvents was tested, including DMSO (dimethyl sulfoxide), THF (tetrahydrofuran), deionized water, alkaline water $(0.1 \mathrm{M} \mathrm{NaOH})$, and aqueous solution of $\mathrm{NaNO}_{3}$ and $\mathrm{NaHCO}_{3}(0.1 \mathrm{M})$. A qualitative evaluation of the solubility was determined by ranking the visual turbidity of the solution.

\section{Enzymatic Hydrolysis of Hemicellulose}

The freeze-dried isolated hemicellulose was hydrolyzed with purified endo- $\beta-(1-$ 4)-xylanase obtained from Thermomyces lanuginosus at $\mathrm{pH} 4$ (citrate buffer) at an enzyme dosage of $125 \mathrm{U} / \mathrm{g}$ of substrate. The incubation temperature was set at $50{ }^{\circ} \mathrm{C}$ at $100 \mathrm{rpm}$ in a shaker incubator. The liquid fraction containing the hydrolyzed products (sugars) were monitored as a function of time $(4,24,36,48$, and $72 \mathrm{~h})$ by high-performance liquid chromatography-refractive index detection (HPLC-RID) according to the procedure mentioned in section 'Chemical composition of hemicellulose'.

\section{RESULTS AND DISCUSSION}

This research aims to extract hemicellulose in polymeric form from mixed eucalyptus sawdust while minimizing chain degradation by using an alkali mediated hydrothermal approach. The strategy is to develop a method that could be implemented at industrial scale and integrated with a conventional biomass pulping process (Fig. 1).

\section{Chemical Composition of Eucalyptus Sawdust}

Compositional analysis indicated that the mixed sawdust used in this study was predominantly Eucalyptus grandis, the species most used for pulp and papermaking in Australia (Nolan et al. 2005). The composition of the biomass (Table S1) was cellulose (43.2\%), hemicellulose (32.0\%), and lignin (20.2\%). The contents of the eucalyptus sawdust compare well with the ranges reported in literature (Ona et al. 1995; Rencoret et al. 2005).

\section{Yield of Hemicellulose}

Hemicellulose was recovered from the eucalyptus sawdust using an alkali-mediated hydrothermal approach. In this study, the temperature was fixed $121{ }^{\circ} \mathrm{C}$ (autoclave) throughout all the experiments. The only variables were extraction time and concentration of alkali. With increasing extraction time and alkali concentration, a proportional increase in the recovery of hemicellulose was observed (Fig. 2). This result agrees with the literature (Singh et al. 2018). At the extraction time of $2.5 \mathrm{~h}$ with $15 \%$ alkali and a solid to liquid dilution ratio of $1: 10,35$ to $37 \%$ (specific yield) of the native hemicellulose was recovered from the eucalyptus sawdust. At this stage, the specific yield of hemicellulose reached an optimum and did not improve further in response to increasing alkali concentration. Current trend for specific yield revealed that extraction time played the most important role in hemicellulose recovery, followed by alkali concentration, which also showed a strong influence. Although the overall yield of hemicellulose in the present study is lower in comparison to those reported in literature (Table 1), it is to be noted that prior studies have utilized bleached or delignified biomass in combination with different extraction 
conditions. In this study, unbleached eucalyptus sawdust has been used, such that the lignin component can interfere in the hemicellulose extraction process (Singh et al. 2018).

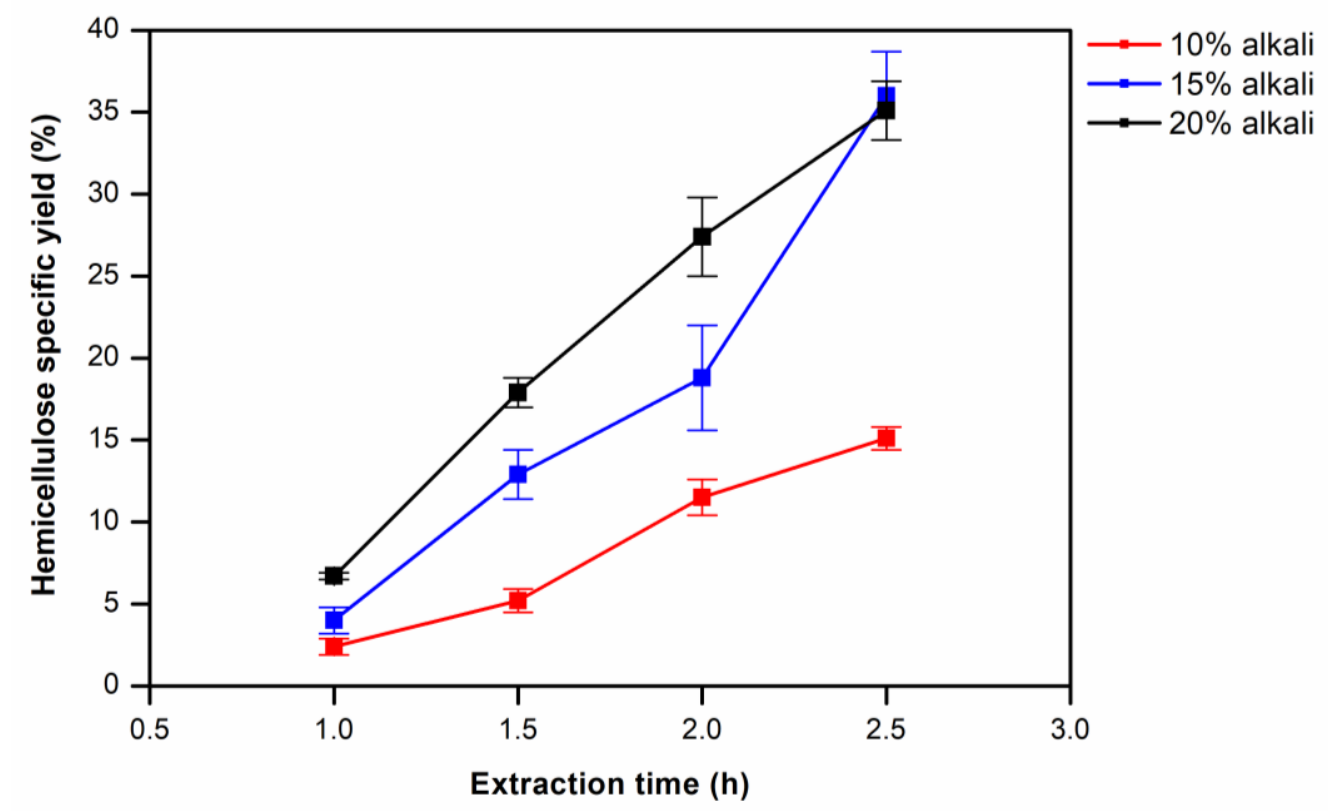

Fig. 2. Specific yield of hemicellulose with increasing extraction time and alkali

Post hemicellulose extraction, the composition of the residual biomass was analyzed to determine the content of cellulose, hemicellulose, and lignin. Following extraction for $2.5 \mathrm{~h}$ at $15 \%$ alkali, $~ 37 \%$ of the original hemicellulose was isolated. The corresponding composition of the residual biomass is shown in Fig. 3. The mass balance revealed that the residual biomass was cellulose enriched with proportional decreases in both hemicellulose and lignin content with increasing extraction time (Table S3).

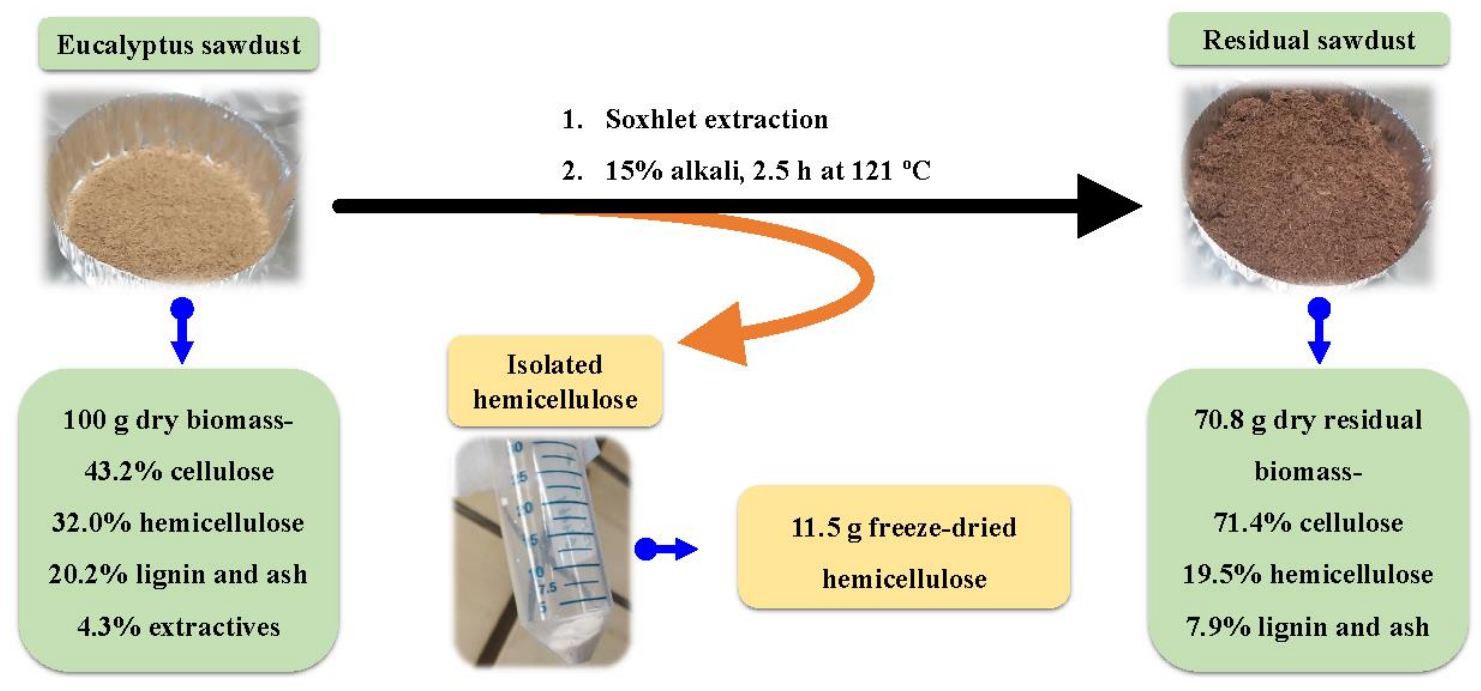

Fig. 3. Composition of the residual biomass post extraction of hemicellulose for $2.5 \mathrm{~h}$ with $15 \%$ alkali 


\section{Purification of Crude Hemicellulose}

The crude hemicellulose precipitate was dark in colour, indicating lignin contamination. Washing with either ethanol or an ethanol-water $(1: 1)$ mixture showed limited improvement. Washing with deionized water was shown visually to be the most effective method for lignin removal. After multiple water washes, the freeze-dried hemicellulose was almost white with a slight yellowish hue (Fig. S2).

To determine the purity of the isolated hemicellulose, TGA was performed on the final freeze-dried samples (Fig. 4). In the first stage of the thermal cycle, moisture loss was indicated by the initial mass loss $(\sim 5 \%)$ around 50 to $120^{\circ} \mathrm{C}$. In the second stage, thermal degradation was observed between 230 to $350{ }^{\circ} \mathrm{C}$, as reported in the literature (Banerjee $e t$ al. 2019). In this temperature range, the isolated hemicellulose showed a major mass loss of approximately $46 \%$, which can be attributed to depolymerization and structural degradation of the amorphous hemicellulose to the corresponding hydrocarbons $\left(\mathrm{CH}_{3} \mathrm{COOH}, \mathrm{CH}_{4}, \mathrm{CO}\right.$, and $\left.\mathrm{CO}_{2}\right)$ (Sivasangar et al. 2013). A further mass loss of approximately $22 \%$ was observed between 600 to $800{ }^{\circ} \mathrm{C}$, due to the continuous decomposition of the residue. The mass remaining at $800{ }^{\circ} \mathrm{C}$ was the char content of the sample. At this stage, the environment was changed from nitrogen to oxygen. With the introduction of oxygen, combustion was initiated, and an instant mass loss was observed (Fig. 4). This corresponded to the loss of residual organic matter in the char. The residual mass is the inorganic filler or ash content.

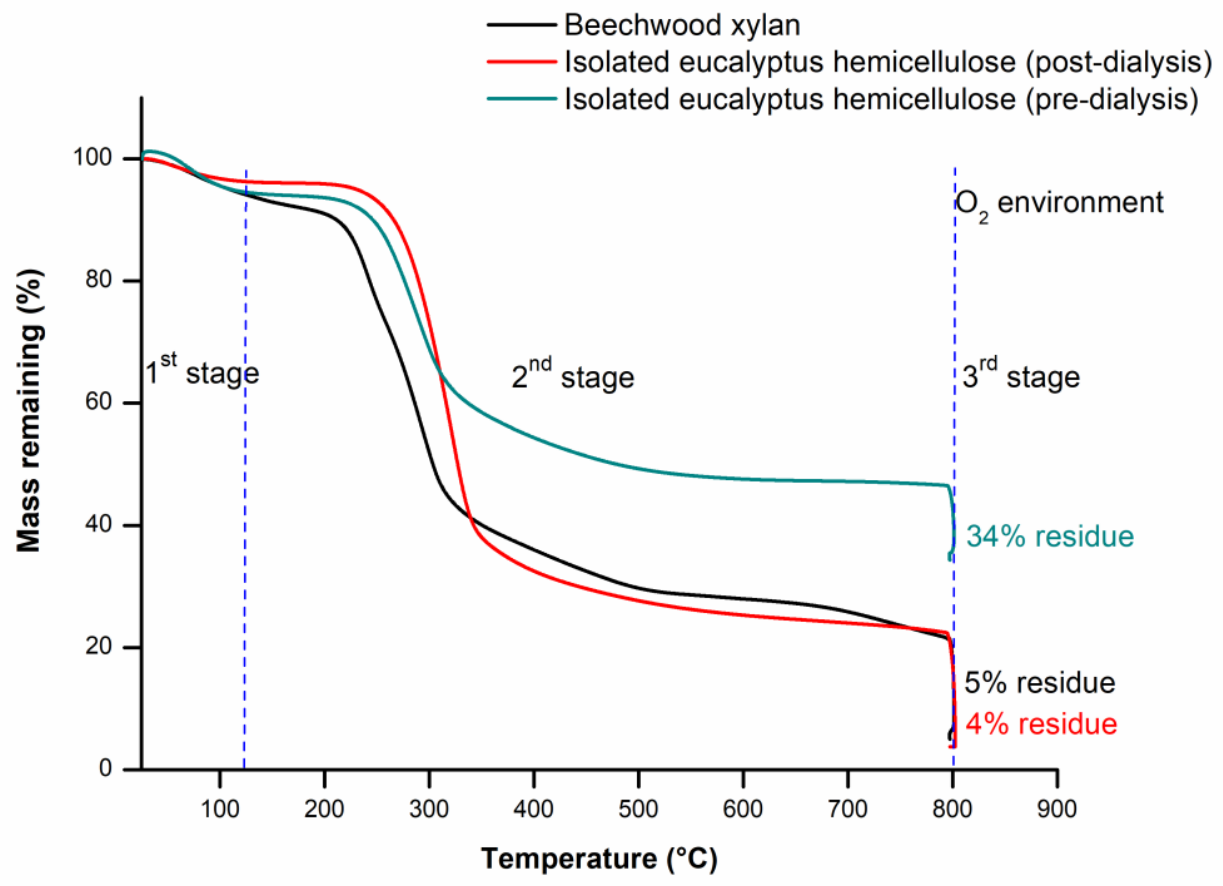

Fig. 4. TGA profile of commercial beechwood xylan and isolated eucalyptus hemicellulose preand post-dialysis

A critical finding in this study is that the co-precipitation of salt (inorganics) occurs during the hemicellulose neutralization. Figure 4 demonstrates that this salt was not effectively removed by water-washing, as the residual salt content in the freeze-dried hemicellulose after water-washing was only $\sim 30 \%$ (Fig. 4). This is attributed to salts 
formed during the $\mathrm{pH}$ neutralization that can adhere to the hemicellulose precipitate through weak interaction with the hydroxyl groups of hemicelluloses. To remove these unwanted salts, the water-washed product was dialyzed to remove the residual salt (final conductivity was below $10 \mu \mathrm{S}$ and stable) and then freeze-dried (Fig. 4). The residue obtained at the end of this stage corresponds to the true ash content of the samples, which was below 5\% in the isolated eucalyptus hemicellulose (post-dialysis).

Additionally, in this study commercial beechwood xylan was used as a comparator, because xylan is the major form of hemicellulose known in hardwoods (Sharma et al. 2020). The observed difference between the thermal behavior of the commercial beechwood xylan (black line) and the post-dialysis isolated eucalyptus hemicellulose (red line) could be a result of their inherent structural differences. Hemicellulose is a heterogeneous polymer, the composition of which is known to vary as a function of source. Hence, the physical and the chemical properties of hemicelluloses from two different sources may not be exactly similar.

For large-scale application of hemicellulose, salt removal can be an additional step. The impact of residual salt in the isolated xylan has been investigated in the context of films and packaging. It was found that presence of salt allowed superior film formation (Bahcegul et al. 2014). Thus, depending on the targeted end application, salt removal can be optional.

\section{Composition of the Isolated Eucalyptus Hemicellulose}

The compositional analysis determined by HPLC indicated that the isolated hemicellulose was predominantly a glucoroxylan (xylose with 4-O-methylglucopyranosyl uronic acid as substituents), a typical xylan found in hardwoods such as Eucalyptus grandis (Shatalov et al. 1999; Togashi et al. 2009). A lower acetic acid concentration indicated that deacetylation occurred during the alkali-mediated hydrothermal extraction, wherein the acetyl groups inherently present in the hemicellulose backbone are lost during the process. The xylose to glucuronic acid ratio in the isolated hemicellulose was approximately 11:1, which is within the range known for hardwood xylans (Togashi et al. 2009). The acidinsoluble lignin (including ash) was below 5\%, showing the high-purity of the isolated hemicellulose (>95\%). Other sugars, such as galactose, previously reported in eucalyptus xylans (Shatalov et al. 1999) were not detected.

Table 2. Composition of the Isolated Eucalyptus Hemicellulose

\begin{tabular}{|c|c|c|c|c|c|}
\hline Component & Xylose (\%) & Glucose (\%) & $\begin{array}{c}\text { Glucuronic } \\
\text { Acid (\%) }\end{array}$ & $\begin{array}{c}\text { Acetic Acid } \\
(\%)\end{array}$ & $\begin{array}{c}\text { Lignin }^{\star} \\
(\%)\end{array}$ \\
\hline $\begin{array}{c}\text { Isolated } \\
\text { eucalyptus } \\
\text { hemicellulose }\end{array}$ & $77.9 \pm 1.4$ & $6.7 \pm 1.0$ & $7.2 \pm 0.3$ & $0.4 \pm 0.2$ & $4.3 \pm 0.6$ \\
\hline
\end{tabular}

*: Ash included

\section{Further Characterization of the Isolated Eucalyptus Hemicellulose}

The physiochemical characterization of the isolated eucalyptus hemicellulose was achieved by FTIR, solid state NMR $\left({ }^{13} \mathrm{C}\right)$, SEC, surface morphology (Fig. S3), and elemental analysis (Table S2).

The FTIR profiles of both a commercial beechwood xylan and the isolated eucalyptus hemicellulose are similar, as shown in Fig. 5. The isolated eucalyptus hemicellulose spectrum has all the characteristic features of a typical xylan. A broad 
absorption around the region of 3300 to $2900 \mathrm{~cm}^{-1}$ can be attributed to the presence of hydroxyl and methyl groups. The absorbance at 2900, 1600, 1460, 1370, and $1024 \mathrm{~cm}^{-1}$ can be attributed to the xylan moiety (Singh et al. 2018; Xu et al. 2018). The band between 1166 and $1042 \mathrm{~cm}^{-1}$ is typical of a hemicellulose polymer. The sharp band at $896 \mathrm{~cm}^{-1}$ is characteristic of the $\beta$-glycosidic linkage between xylose monomer units. The absorption at $1600 \mathrm{~cm}^{-1}$ can be associated with the $\mathrm{C}=\mathrm{O}$ stretch of carboxylate groups present in the hemicellulose. A strong absorption band at $1024 \mathrm{~cm}^{-1}$ is due to $\mathrm{C}-\mathrm{O}$ stretching, $\mathrm{C}-\mathrm{C}$ stretching, or $\mathrm{C}-\mathrm{OH}$ bending (Singh et al. 2018).

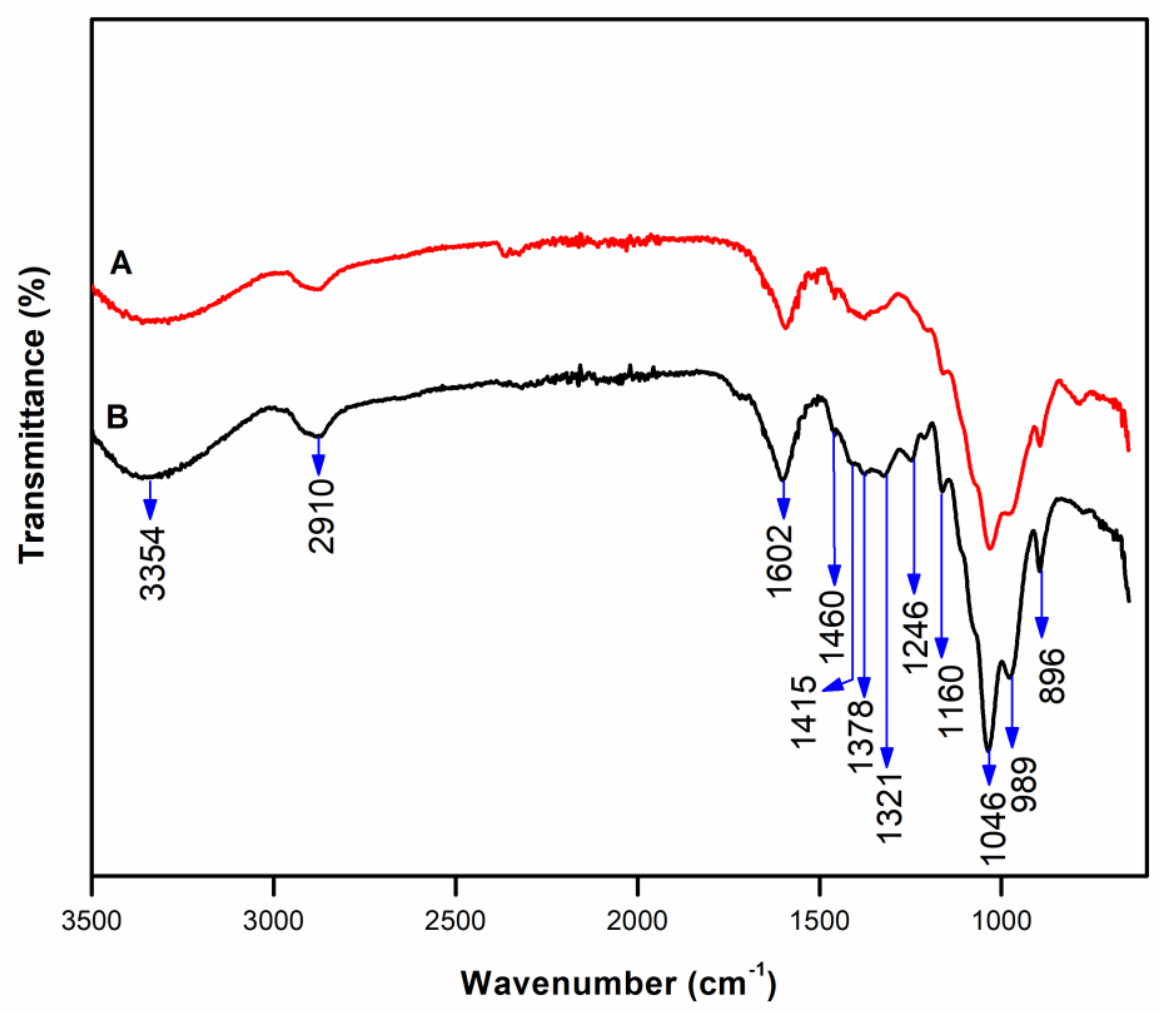

Fig. 5. FTIR spectra of (A) commercial beechwood xylan and (B) isolated eucalyptus hemicellulose

Solid state ${ }^{13} \mathrm{C}$ NMR provided complementary information on the structure of the isolated hemicellulose (Fig. 6). The corresponding signals for the carbons were found between 60 to $110 \mathrm{ppm}$, like those reported in literature (Hettrich et al. 2005). The isolated hemicellulose showed no evidence of lignin contamination, as no peaks were observed in the region 104 to $168 \mathrm{ppm}$, where aromatic carbon peaks from lignin would be expected (She et al. 2010). Typically, the acetyl methyl group would be expected to show signals in the region of 20 to $30 \mathrm{ppm}$ and would be observed concurrently with the carbonyl peak at $\sim 170 \mathrm{ppm}$. The absence of peaks in these two regions of the ${ }^{13} \mathrm{C}$ NMR of the isolated eucalyptus hemicellulose, may indicate loss of the acetyl groups due to hydrolysis in the alkali extraction. It is also possible that any residual acetyl groups did not show up, as they were below detection in the ${ }^{13} \mathrm{C}$ NMR spectrum. Overall, the FTIR and ${ }^{13} \mathrm{C}$ NMR profiles confirmed the typical characteristics of xylan for the isolated hemicellulose. 


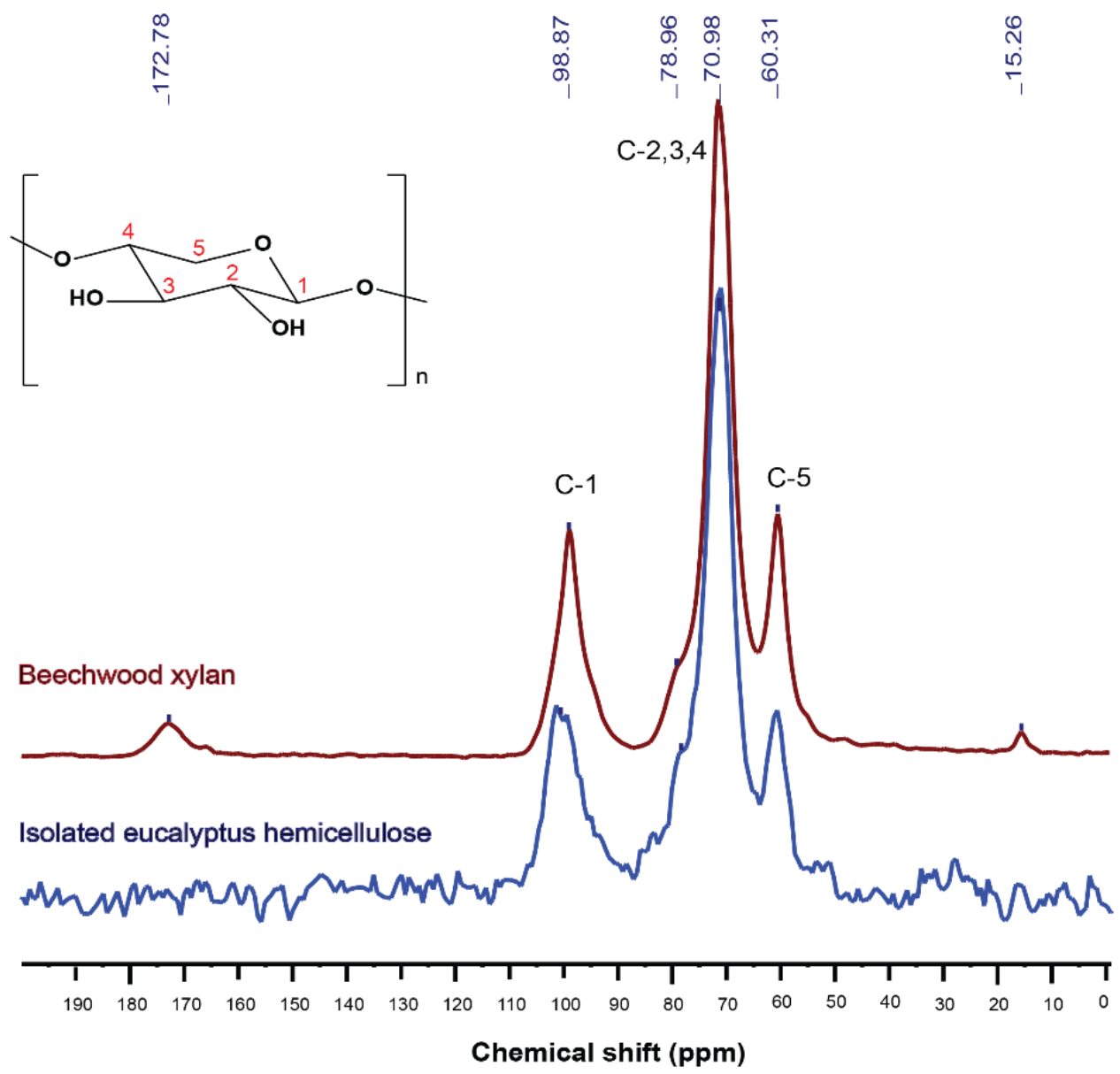

Fig. 6. CP/MAS ${ }^{13} \mathrm{C}$ NMR spectra of commercial beechwood xylan and isolated eucalyptus hemicellulose

\section{SEC of isolated eucalyptus hemicellulose}

Extended extraction time and higher alkali concentration tend to improve the yield of hemicellulose. However, increasing alkali concentration and temperature can be detrimental, causing depolymerization and resulting in lower molecular weight hemicellulose compounds that are easier to extract (Hutterer et al. 2016). It is additionally known that at high alkalinity ( $\mathrm{pH} 12$ to 14 ) and temperatures of around $100{ }^{\circ} \mathrm{C}$, a peeling reaction takes place that can degrade polysaccharides by dissolving the reducing end groups (Farhat et al. 2017). Thus, the hemicellulose fractions obtained under varying extraction conditions were studied by SEC for their weight-average $\left(M_{\mathrm{w}}\right)$, number-average $\left(M_{\mathrm{n}}\right)$, and polydispersity $\left(M_{\mathrm{w}} / M_{\mathrm{n}}\right)$, as shown in Table 3 . The $M_{\mathrm{w}}$ and $M_{\mathrm{n}}$ values of the hemicellulose fractions were similar and did not change with increasing alkali concentration, indicating that they had similar structures and that there was no apparent degradation of the hemicellulose with increasing alkalinity. Interestingly, the structural heterogeneity indicated by the polydispersity index ranged from 1.10 to 1.43 . The hemicellulose extracted had a surprisingly narrow molecular weight distribution, which is unusual for biopolymers. Further, the $M_{\mathrm{w}}$ values of the isolated hemicelluloses were relatively low. This suggested a diffusion-controlled mechanism in which the solubility and diffusion of hemicellulose polymer from the fibrous structure represents the limiting step. 
Table 3. Weight-average $\left(M_{\mathrm{w}}\right)$, Number-average $\left(M_{\mathrm{n}}\right)$, and Polydispersity Index $\left(M_{\mathrm{w}} / M_{\mathrm{n}}\right)$ of the Isolated Eucalyptus Hemicellulosic Fractions

\begin{tabular}{|c|c|c|c|c|c|}
\hline $\begin{array}{c}\text { Hemicellulose } \\
\text { Fractions }^{*}\end{array}$ & $\begin{array}{c}\text { Alkali } \\
\text { Concentration (\%) }\end{array}$ & $\begin{array}{c}\text { Extraction Time } \\
\text { (h) }\end{array}$ & $\boldsymbol{M}_{\mathbf{n}}$ & $\boldsymbol{M}_{\mathbf{w}}$ & $\boldsymbol{M}_{\mathbf{w}} / \boldsymbol{M}_{\mathbf{n}}$ \\
\hline $\mathrm{H} 1$ & 10 & 1 & 19,616 & 21,610 & 1.10 \\
\hline $\mathrm{H} 2$ & 10 & 1.5 & 18,731 & 22,189 & 1.19 \\
\hline $\mathrm{H} 3$ & 10 & 2 & 17,806 & 24,372 & 1.37 \\
\hline $\mathrm{H} 4$ & 10 & 2.5 & 19,831 & 26,774 & 1.35 \\
\hline $\mathrm{H} 5$ & 15 & 1 & 18,943 & 23,183 & 1.22 \\
\hline $\mathrm{H} 6$ & 15 & 2 & 19,288 & 21,794 & 1.13 \\
\hline $\mathrm{H} 7$ & 15 & 2.5 & 21,872 & 24,964 & 1.14 \\
\hline $\mathrm{H} 8$ & 15 & 1 & 21,680 & 30,946 & 1.43 \\
\hline $\mathrm{H} 9$ & 20 & 1.5 & 17,163 & 21,825 & 1.27 \\
\hline $\mathrm{H} 10$ & 20 & 2 & 21,441 & 24,104 & 1.24 \\
\hline $\mathrm{H} 11$ & 20 & 2.5 & 22,037 & 30,146 & 1.39 \\
\hline $\mathrm{H} 12$ & 20 & 20,761 & 1.40 \\
\hline
\end{tabular}

*: $\mathrm{H1}, \mathrm{H} 2, \mathrm{H} 3, \mathrm{H} 4, \mathrm{H} 5, \mathrm{H} 6, \mathrm{H} 7, \mathrm{H} 8, \mathrm{H} 9, \mathrm{H} 10, \mathrm{H} 11$, and $\mathrm{H} 12$ are the different hemicellulose fractions collected with varying alkali and time of extraction

\section{Solubility of the Isolated Eucalyptus Hemicellulose}

A brief solubility study was undertaken to understand the affinity of the isolated eucalyptus hemicellulose for different solvents, as shown in Table 4. This information will be useful when developing new applications for the isolated material. The solubility of the isolated hemicellulose in water was $\mathrm{pH}$-dependent, and it was practically insoluble in deionized water. Solubility improved at higher $\mathrm{pH}$ and was highest at $(20 \mathrm{mg} / 10 \mathrm{~mL})$ in $0.1 \mathrm{M} \mathrm{NaOH}$ in deionized water, followed by $0.1 \mathrm{M}$ solutions of $\mathrm{NaNO}_{3}$ and $\mathrm{NaHCO}_{3}$. The solute-solvent interaction for hemicellulose depends on many factors, such as the degree of polymerization, nature of the original biomass and substituents, and the different branching of the polymer. The extensive H-bonding tendency along the polymer chains is effectively reduced at higher $\mathrm{pH}$, resulting in higher solubility (Kantelinen et al. 1993). Among the organic solvents, isolated hemicellulose was partially soluble in DMSO (1 $\mathrm{mg} / \mathrm{mL})$, and the solubility improved with increasing temperature $\left(70{ }^{\circ} \mathrm{C}\right)$ and incubation time $(15 \mathrm{~h})$. Hemicellulose remained practically insoluble in THF under these conditions.

Table 4. Qualitative Evaluation of Solubility of the Isolated Eucalyptus Hemicellulose

\begin{tabular}{|c|c|c|c|c|c|}
\hline Component & $0.1 \mathrm{M} \mathrm{NaOH}$ & $\begin{array}{c}\mathbf{0 . 1 ~ M} \\
\mathrm{NaNO}_{3} \text { and } \\
\mathrm{NaHCO3}\end{array}$ & DMSO & $\begin{array}{c}\text { Deionized } \\
\text { water }\end{array}$ & THF \\
\hline $\begin{array}{c}\text { Isolated } \\
\text { eucalyptus } \\
\text { hemicellulose }\end{array}$ & +++ & ++ & + & - & - \\
\hline
\end{tabular}

'+' indicates higher solubility, '-' indicates lower solubility

\section{Production of Xylooligosaccharides}

The isolated eucalyptus hemicellulose was hydrolyzed to produce low molecular weight xylooligosaccharides (XOS) with varying degree of polymerization (DP) via enzymatic treatment with endo- $\beta-(1-4)$-xylanse from Thermomyces lanuginosus. Xylose (DP1), xylobiose (DP2), and xylotriose (DP3) were the major hydrolysis products (Fig. 7). Endo- $\beta-(1-4)$-xylanase can catalyze hydrolysis of xylan through cleavage of the $\beta-(1-4)$ 
glycosidic linkages (Sørensen et al. 2007) present along the polymer chain. In general, this endo-xylanase preferentially acts on the longer xylooligomers, hydrolyzing them into smaller xylobiose and xylotriose (Polizeli et al. 2005). Consequently, for reaction times up to approximately $4 \mathrm{~h}$, xylotriose was the predominant oligomer, followed by xylobiose. After $24 \mathrm{~h}$ of hydrolysis, xylobiose became the dominant oligosaccharide product while xylotriose concentration showed a gradual decline. With extended reaction time of up to $48 \mathrm{~h}$, the total concentration of XOS reached a maximum, mainly driven by increasing xylobiose. Initially, xylose release was low in the hydrolysate up to $12 \mathrm{~h}$, after which a proportional increase was observed with increasing time up to $72 \mathrm{~h}$. The consistent increase in xylobiose and xylose concentrations indicated that longer contact time results in exhaustion of longer chain xylans, leading to subsequent and sequential depolymerisation of the higher molecular weight oligomers, i.e., depletion of xylotriose and increase in xylobiose and xylose.

The hydrolysis products may be recovered using ultra-filtration or chromatographic separation techniques, but this was not pursued in this study. Xylooligomers (DP2 to DP3) are non-digestible oligosaccharides that exhibit great prebiotic properties and are useful for other applications, including development of novel surfactants and emulsifiers (Naidu et al. 2018), while xylose is a valuable sugar used for the production of xylitol (Granström et al. 2007). Depending on the end application, the enzyme reaction can be tuned as per the requirement. If oligosaccharides with higher DP are desired, hydrolysis time should be reduced, while if the smaller oligomers are targeted then a longer hydrolysis will be preferred. Additionally, a total conversion of xylan to xylose is possible through a combination of enzymes, such as xylanase along with $\beta$-xylosidase and esterase (Biely et al. 2016). Thus, a range of products can be obtained by monitoring the time of hydrolysis and the enzymes used.

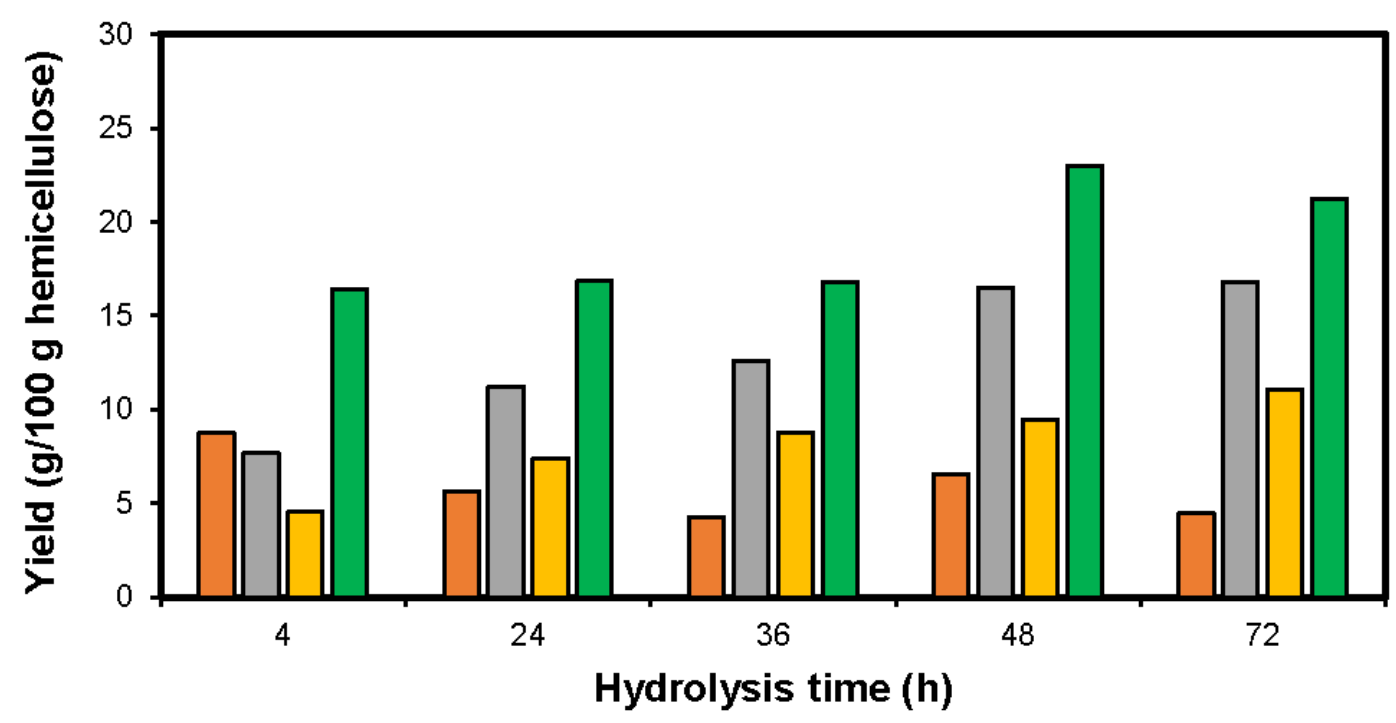

aX3 aX2 aX1 aXOS (DP 3-2)

Fig. 7. Enzymatic hydrolysis of the isolated eucalyptus hemicellulose as a function of time showing yield of xylotriose (X3, DP 3), xylobiose (X2, DP 2) and XOS (DP 3-2) 


\section{CONCLUSIONS}

1. A simple alkali-assisted hydrothermal approach to isolate hemicellulose from unbleached eucalyptus sawdust was investigated. The chemical and spectroscopic characterization of the isolated hemicellulose showed a typical hardwood xylan composition, with xylose as the repeating unit along with glucose, glucuronic acid, and acetyl groups substituted along the polymer backbone.

2. The polydispersity index of the isolated hemicellulose ranged between values of 1.10 to 1.43 , indicating a narrow molecular weight distribution. The NMR highlighted the fact that isolated hemicellulose was mostly deacetylated with low lignin contamination.

3. Enzymatic treatment of the isolated hemicellulose produced high value xylooligosaccharides, yielding $\sim 25 \mathrm{~g} / 100 \mathrm{~g}$ of hemicellulose that can be further used for different applications.

4. The optimized process has the advantage of minimum chemical usage, as the alkali used for extraction can be recovered from the subsequent kraft process. The coextracted lignin can be recovered from the ethanol fraction and utilized further. The residual solid generated by the process is rich in cellulose with lower hemicellulose and lignin content. Therefore, it would be interesting to study the products (pulps or paper) obtained from diverting the remaining solid material back into an industrial pulping process as a step towards integrating the two processes in a biorefinery.

\section{ACKNOWLEDGMENTS}

The authors gratefully acknowledge the Australian Research Council (ARC) for financial support through the Industry Transformation Research Hub Processing Advance Lignocellulosics (PALS) Grant IH130100016, the Monash X-ray Platform (Monash Centre for Electron Microscopy), and the Universite' of Sherbrooke, Canada, for hosting author DG for a research experience visit.

\section{REFERENCES CITED}

Aachary, A. A., and Prapulla, S. G. (2011). "Xylooligosaccharides (XOS) as an emerging prebiotic: Microbial synthesis, utilization, structural characterization, bioactive properties, and applications," Comprehensive Reviews in Food Science and Food Safety 10(1), 2-16. DOI: 10.1111/j.1541-4337.2010.00135.x

Al-Dajani, W. W., and Tschirner, U. W. (2008). "Pre-extraction of hemicelluloses and subsequent kraft pulping Part I: Alkaline extraction," TAPPI Journal 7(6), 3-8. DOI: 10.7584/JKTAPPI.2017.04.49.2.30

ASTM E1721-01 (2015). "Standard test method for determination of acid-insoluble residue in biomass," ASTM International, West Conshohocken, PA, USA.

ASTM E1755-01 (2015). "Standard test method for ash in biomass," ASTM International, West Conshohocken, PA, USA.

Bahcegul, E., Toraman, H. E., Erdemir, D., Akinalan, B., Ozkan, N., and Bakir, U. (2014). "An unconventional approach for improving the integrity and mechanical 
properties of xylan type hemicellulose based film," RSC Advances 4(64), 3411734126. DOI: 10.1039/c4ra05109b

Banerjee, S., Patti, A. F., Ranganathan, V., and Arora, A. (2019). "Hemicellulose based biorefinery from pineapple peel waste: Xylan extraction and its conversion into xylooligosaccharides," Food and Bioproducts Processing 117, 38-50. DOI: 10.1016/j.fbp.2019.06.012

Bhutto, A. W., Qureshi, K., Harijan, K., Abro, R., Abbas, T., Bazmi, A. A., Karim, S., and $\mathrm{Yu}, \mathrm{G}$. (2017). "Insight into progress in pre-treatment of lignocellulosic biomass," Energy 122, 724-745. DOI: 10.1016/j.energy.2017.01.005

Biely, P., Singh, S., and Puchart, V. (2016). "Towards enzymatic breakdown of complex plant xylan structures: State of the art," Biotechnology Advances 34(7), 1260-1274. DOI: 10.1016/j.biotechadv.2016.09.001

Castaldi, M., Van Deventer, J., Lavoie, J. M., Legrand, J., Nzihou, A., Pontikes, Y., Py, X., Vandecasteele, C., Vasudevan, P. T., and Verstraete, W. (2017). "Progress and prospects in the field of biomass and waste to energy and added-value materials," Waste and Biomass Valorization 8(6), 1875-1884. DOI: 10.1007/s12649-017-0049-0

Chen, M., Lu, J., Cheng, Y., Li, Q., and Wang, H. (2019). "Novel process for the coproduction of xylo-oligosaccharide and glucose from reed scraps of reed pulp mill," Carbohydrate Polymers 215, 82-89. DOI: 10.1016/j.carbpol.2019.03.068

Downham, R., Gavran, M., and Frakes, I. (2019). National Wood Processing Survey (Report No. 2019), Australian Bureau of Agricultural and Resource Economics and Sciences, Canberra, Australia.

Farhat, W., Venditti, R. A., Hubbe, M., Taha, M., Becquart, F., and Ayoub, A. (2017). “A review of water-resistant hemicellulose-based materials: Processing and applications," ChemSusChem 10(2), 305-323. DOI: 10.1002/cssc.201601047

Granström, T. B., Izumori, K., and Leisola, M. (2007). "A rare sugar xylitol. Part II: Biotechnological production and future applications of xylitol," Applied Microbiology and Biotechnology 74(2), 273-276. DOI: 10.1007/s00253-006-0760-4

Hamaguchi, M., Kautto, J., and Vakkilainen, E. (2013). "Effects of hemicellulose extraction on the kraft pulp mill operation and energy use: Review and case study with lignin removal," Chemical Engineering Research and Design 91(7), 1284-1291. DOI: 10.1016/j.cherd.2013.02.006

Hettrich, K., Fischer, S., Schröder, N., Engelhard, J., Drechsler, U., and Loth, F. (2005). "Derivatization and characterization of xylan from oat spelts," Macromolecular Symposia 232(1), 37-48. DOI: 10.1002/masy.200551405

Hutterer, C., Schild, G., and Potthast, A. (2016). "A precise study on effects that trigger alkaline hemicellulose extraction efficiency," Bioresource Technology 214, 460-467. DOI: 10.1016/j.biortech.2016.04.114

Jiang, H., Chen, Q., Ge, J., and Zhang, Y. (2014). "Efficient extraction and characterization of polymeric hemicelluloses from hybrid poplar," Carbohydrate Polymers 101, 1005-1012. DOI: 10.1016/j.carbpol.2013.10.030

Johakimu, J., and Andrew, J. (2013). "Hemicellulose extraction from South African Eucalyptus grandis using green liquor and its impact on kraft pulping efficiency and paper making properties," BioResources 8(3), 3490-3504. DOI: 10.15376/biores.8.3.3490-3504

Kantelinen, A., Rantanen, T., Buchert, J., and Viikari, L. (1993). "Enzymatic solubilization of fibre-bound and isolated birch xylans," Journal of Biotechnology 28(2-3), 219-228. DOI: 10.1016/0168-1656(93)90171-I 
Kim, J. S., Lee, Y. Y., and Kim, T. H. (2016). "A review on alkaline pretreatment technology for bioconversion of lignocellulosic biomass," Bioresource Technology 199, 42-48. DOI: 10.1016/j.biortech.2015.08.085

Marques, A. I., De Lurdes Serrano, M., Alves, A. M. B., and De Sousa, A. P. M. (2019). "Isolation of xylans from bleached eucalyptus kraft pulp by antisolvents precipitation," Cellulose 26(3), 1977-1992. DOI: 10.1007/s10570-018-1941-x

Naidu, D. S., Hlangothi, S. P., and John, M. J. (2018). "Bio-based products from xylan: A review," Carbohydrate Polymers 179, 28-41. DOI: 10.1016/j.carbpol.2017.09.064

Naqvi, M., and Yan, J. (2015). "First-generation biofuels," in: Handbook of Clean Energy Systems, John Wiley \& Sons, Inc., pp. 1-18. DOI:

10.1002/9781118991978.hces207

Nolan, G., Washusen, R., Jennings, S., Greaves, B., and Parsons, M. (2005). Eucalypt Plantations for Solid Wood Products in Australia - A review (Report No. 2005), Forest \& Wood Products Research \& Development Corporation, Victoria, Australia.

Ona, T., Sonoda, T., Shibata, M., and Fukazawa, K. (1995). "Small-scale method to determine the content of wood components from multiple eucalypt samples," TAPPI Journal 78(3), 121-126.

Polizeli, M. L. T. M., Rizzatti, A. C. S., Monti, R., Terenzi, H. F., Jorge, J. A., and Amorim, D. S. (2005). "Xylanases from fungi: Properties and industrial applications," Applied Microbiology and Biotechnology 67(5), 577-591. DOI: 10.1007/s00253-005-1904-7

Rafiqul, I. S. M., and Sakinah, A. M. M. (2013). "Processes for the production of xylitolA review," Food Reviews International 29(2), 127-156. DOI: 10.1080/87559129.2012.714434

Rencoret, J., Gutiérrez, A., and Carlos del Rio, J. (2005). "Chemical composition of different eucalyptus wood species used for paper pulp manufacturing," (http://hdl.handle.net/10261/86415), Accessed 27 Aug 2006.

Rowell, R. M. (2012). Handbook of Wood Chemistry and Wood Composites, Second Edition, CRC Press, Boca Raton, FL, USA.

Samanta, A. K., Jayapal, N., Kolte, A. P., Senani, S., Sridhar, M., Suresh, K. P., and Sampath, K. T. (2012). "Enzymatic production of xylooligosaccharides from alkali solubilized xylan of natural grass (Sehima nervosum)," Bioresource Technology 112, 199-205. DOI: 10.1016/j.biortech.2012.02.036

Shao, H., Hu, Y., Sun, H., Yang, B., Fan, B., and Zhang, H. (2019). "Response surface optimization of alkali extraction and characterization of poplar hemicellulose," BioResources 14(2), 3844-3859. DOI: 10.15376/biores.14.2.3844-3859

Sharma, K., Khaire, K. C., Thakur, A., Moholkar, V. S., and Goyal, A. (2020). “Acacia xylan as a substitute for commercially available xylan and its application in the production of xylooligosaccharides," ACS Omega 5(23), 13729-13738. DOI: 10.1021/acsomega.0c00896

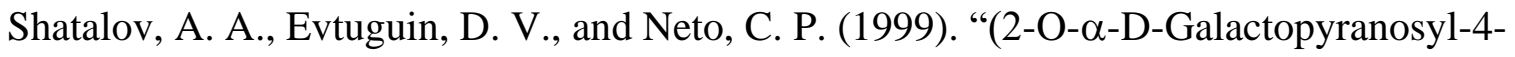
O-methyl- $\alpha$-D-glucurono)-D-xylan from Eucalyptus globulus Labill," Carbohydrate Research 320(1-2), 93-99. DOI: 10.1016/S0008-6215(99)00136-6

She, D., Xu, F., Geng, Z. C., Sun, R. C., Jones, G. L., and Baird, M. S. (2010). "Physicochemical characterization of extracted lignin from sweet sorghum stem," Industrial Crops and Products 32(1), 21-28. DOI: 10.1016/j.indcrop.2010.02.008

Singh, R. D., Banerjee, J., Sasmal, S., Muir, J., and Arora, A. (2018). "High xylan recovery using two stage alkali pre-treatment process from high lignin biomass and 
its valorisation to xylooligosaccharides of low degree of polymerisation," Bioresource Technology 256, 110-117. DOI: 10.1016/j.biortech.2018.02.009

Sivasangar, S., Taufiq-Yap, Y. H., Zainal, Z., and Kitagawa, K. (2013). "Thermal behavior of lignocellulosic materials under aerobic/anaerobic environments," International Journal of Hydrogen Energy 38(36), 16011-16019. DOI: 10.1016/j.ijhydene.2013.09.083

Sluiter, A., Ruiz, R., Scarlata, C., Sluiter, J., and Templeton, D. (2008). "Determination of extractives in biomass," (NREL/TP-510-42619), National Renewable Energy Laboratory, Golden, CO, USA.

Sørensen, H. R., Pedersen, S., Jørgensen, C. T., and Meyer, A. S. (2007). "Enzymatic hydrolysis of wheat arabinoxylan by a recombinant 'minimal' enzyme cocktail containing $\beta$-xylosidase and novel endo-1,4- $\beta$-xylanase and $\alpha$-L-arabinofuranosidase activities," Biotechnology Progress 23(1), 100-107. DOI: 10.1021/bp0601701

Svärd, A., Brännvall, E., and Edlund, U. (2017). "Rapeseed straw polymeric hemicelluloses obtained by extraction methods based on severity factor," Industrial Crops and Products 95, 305-315. DOI: 10.1016/j.indcrop.2016.10.038

Togashi, H., Kato, A., and Shimizu, K. (2009). "Enzymatically derived aldouronic acids from Eucalyptus globulus glucuronoxylan," Carbohydrate Polymers 78(2), 247-252. DOI: 10.1016/j.carbpol.2009.03.035

Vila, C., Romero, J., Francisco, J. L., Santos, V., and Parajó, J. C. (2012). "On the recovery of hemicellulose before kraft pulping," BioResources 7(3), 4179-4189. DOI: 10.15376/biores.7.3.4179-4189

Warden, A. C., and Haritos, V. S. (2008). Future Biofuels for Australia - Issues and Opportunities for Conversion of Second Generation Lignocellulosics (Report No. 2008), Rural Industries Research and Development Corporation, Canberra, Australia.

Wu, Y., Wu, J., Yang, F., Tang, C., and Huang, Q. (2019). "Effect of $\mathrm{H}_{2} \mathrm{O}_{2}$ bleaching treatment on the properties of finished transparent wood," Polymers 11(5), 1-13. DOI: 10.3390/polym 11050776

Xu, J. Y., Yuan, T. Q., Xiao, L., and Sun, R. C. (2018). "Effect of ultrasonic time on the structural and physico-chemical properties of hemicelluloses from Eucalyptus grandis," Carbohydrate Polymers 195, 114-119. DOI: 10.1016/j.carbpol.2018.04.067

Article submitted: September 10, 2020; Peer review completed: January 24, 2021;

Revised version received: February 4, 2021; Accepted: February 5, 2021; Published:

February 17, 2021.

DOI: 10.15376/biores.16.2.2524-2547 


\section{APPENDIX}

\section{SUPPLEMENTARY INFORMATION}

\section{Chemical Composition}

Table S1. Chemical Composition of Eucalyptus Sawdust

\begin{tabular}{|c|c|c|}
\hline & \multicolumn{2}{|c|}{ Content ( $\% \pm$ Standard Deviation) } \\
\hline Component & $\begin{array}{l}\text { Obtained Values } \\
\text { for Eucalyptus } \\
\text { Sawdust }\end{array}$ & $\begin{array}{c}\text { Reported Values } \\
\text { for Eucalyptus } \\
\text { grandis (Ona et al. } \\
1995)\end{array}$ \\
\hline Cellulose * & $43.2 \pm 2.5$ & $41.1 \pm 0.6$ \\
\hline Hemicellulose & $32.0 \pm 0.8$ & $38.5 \pm 0.6$ \\
\hline Lignin * & $20.2 \pm 2.2$ & $19.5 \pm 0.7$ \\
\hline Extractives & $4.3 \pm 0.9$ & $4.4 \pm 0.8$ \\
\hline Total & $99.7 \pm 3.5$ & \\
\hline
\end{tabular}

*: Ash included $-0.5 \% \pm 0.04$

\section{Extraction of Hemicellulose}

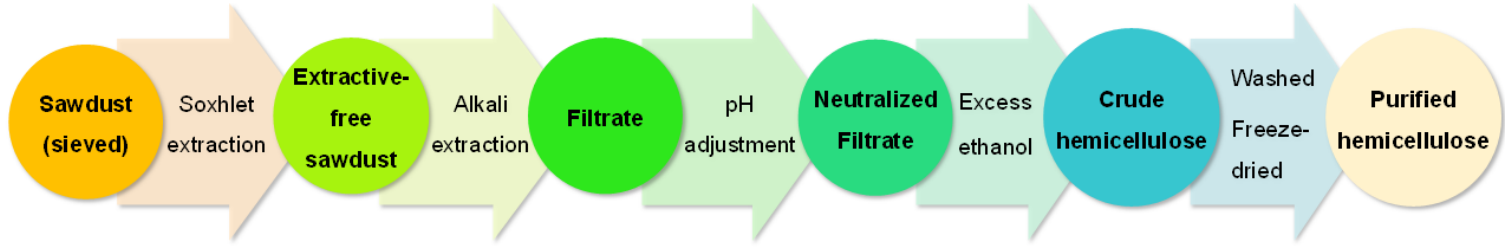

Fig. S1. Schematic of alkali extraction of hemicellulose from eucalyptus sawdust

\section{Purification of Extracted Hemicellulose}

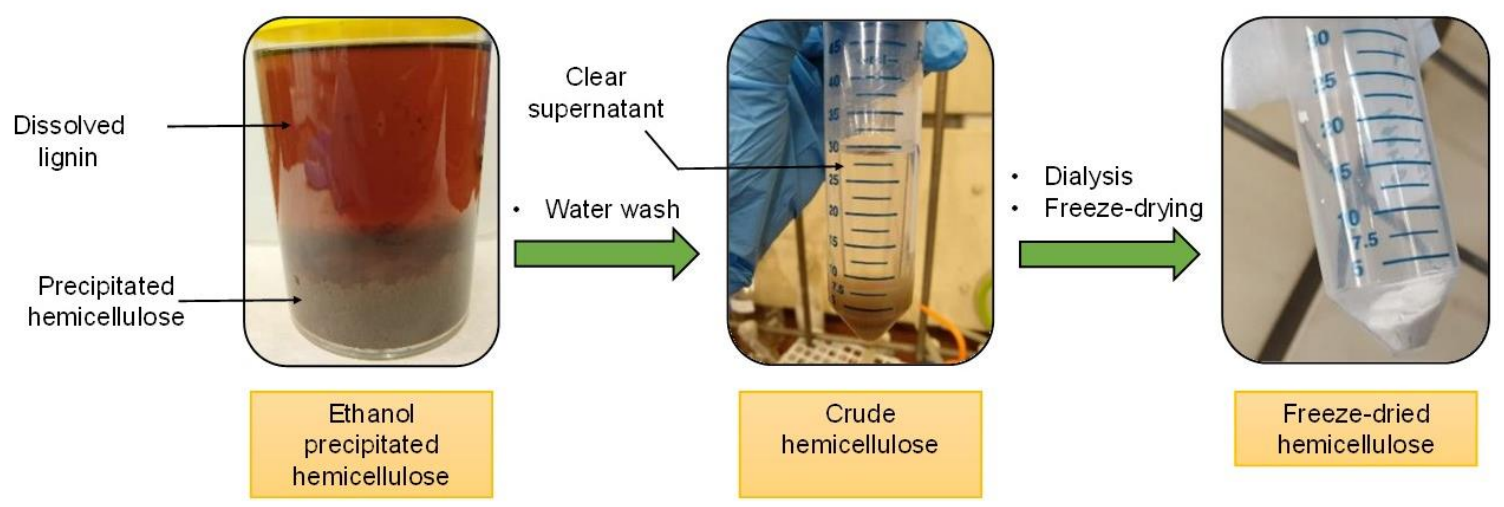

Fig. S2. Stepwise purification of crude hemicellulose 


\section{Elemental Analysis}

The elemental composition ( $\mathrm{CHN}, \mathrm{O}$ by difference) of the extracted hemicellulose fractions was determined using the Perkin Elmer CHNSO elemental analyzer (PerkinElmer Company, Waltham, MA, USA). Oxygen percentage was calculated as the difference remaining after nitrogen, carbon and hydrogen percentages.

The elemental composition of the isolated hemicellulose from eucalyptus sawdust was similar to beechwood xylan in terms of carbon and hydrogen content. However, nitrogen was not detected in the extracted hemicellulose sample.

Table S2. Elemental Composition of Alkali Extracted Hemicellulose and Xylan from Beechwood

\begin{tabular}{|c|c|c|c|c|}
\hline \multirow{2}{*}{ Components } & \multicolumn{4}{|c|}{ Elements (\%) } \\
\cline { 2 - 5 } & Carbon & Hydrogen & Nitrogen & Oxygen \\
\hline Beechwood xylan & 40.2 & 6.2 & 0.1 & 53.5 \\
\hline $\begin{array}{c}\text { Isolated } \\
\text { eucalyptus } \\
\text { hemicellulose }\end{array}$ & 42 & 5.7 & 0 & 52.3 \\
\hline
\end{tabular}

\section{Scanning Electron Microscopy}

The morphological features of the extracted hemicellulose and the biomass pre and post alkali treatment were investigated using a Megellan 400 field emission gun scanning electron microscope (FEGSEM) (Thermo Fisher, Waltham, MA, USA) operating with a 3 $\mathrm{kV}$ electron beam accelerating voltage. Freeze-dried samples were transferred onto carbon stubs coated with iridium (SEM Specimen Stubs 12.5 mm diameter; Agar Scientific Ltd., Stansted, EX, UK) before analysis.

The morphological changes of the biomass resulting from alkali treatment were studied by SEM. Post extraction, the surface of the biomass was more opened up and rough compared to the untreated biomass, which showed a comparatively smoother surface. While the morphology of the extracted hemicellulose showed irregularities with some structures appearing spherical and some more thread-like. 

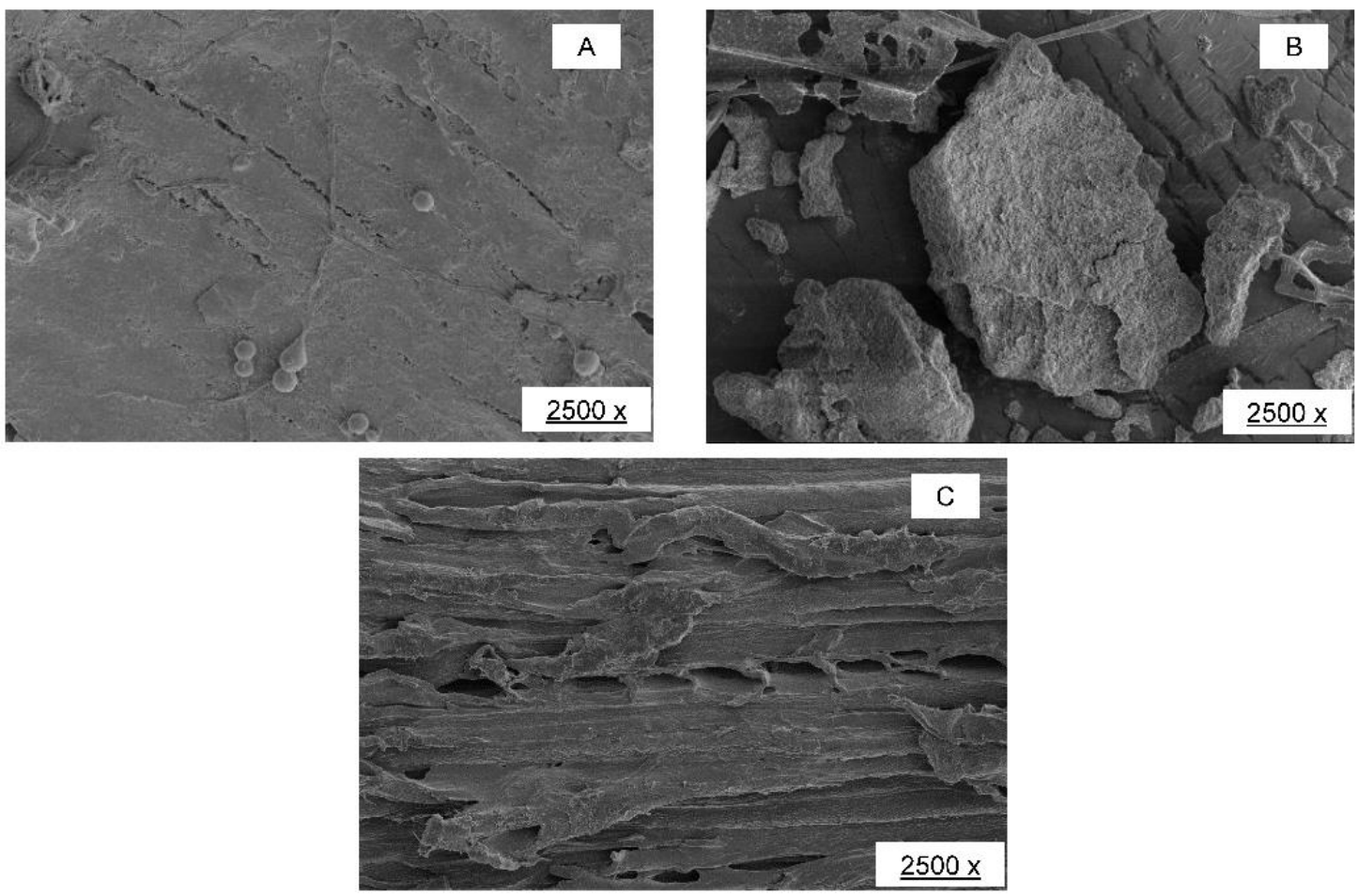

Fig. S3. SEM image (2500 magnification) of (A) untreated sawdust, (B) extracted hemicellulose, and $(C)$ sawdust after alkali treatment

\section{Mass Balance Post Alkali Extraction of Hemicellulose}

Table S3. Composition of Biomass Post Alkali Extraction

\begin{tabular}{|c|c|c|c|c|c|c|c|}
\hline & & & \multicolumn{2}{|c|}{$\begin{array}{c}\text { Recovered } \\
\text { Hemicellulose }\end{array}$} & \multicolumn{3}{c|}{ Residual Biomass } \\
\hline $\begin{array}{c}\text { Extract. } \\
\text { Time } \\
\text { (h) }\end{array}$ & $\begin{array}{c}\text { Te } \\
\mathbf{m p} \\
\left({ }^{\circ} \mathbf{C}\right)\end{array}$ & $\begin{array}{c}\text { Alkali } \\
(\%)\end{array}$ & $\begin{array}{c}\text { Absolute } \\
\text { Yield (\%) }\end{array}$ & $\begin{array}{c}\text { Relative } \\
\text { Yield (\%) }\end{array}$ & $\begin{array}{c}\text { Cellulose } \\
{ }^{*}(\%)\end{array}$ & $\begin{array}{c}\text { Hellulose } \\
\text { (\%) }\end{array}$ & $\begin{array}{c}\text { Lignin * } \\
(\%)\end{array}$ \\
\hline 1.0 & 121 & 10 & $0.8 \pm 0.2$ & $2.4 \pm 0.5$ & $53.5 \pm 1.7$ & $31.3 \pm 1.9$ & $15.5 \pm 0.6$ \\
\hline 1.0 & 121 & 15 & $1.3 \pm 0.3$ & $4.0 \pm 0.8$ & $54.1 \pm 1.8$ & $29.3 \pm 2.9$ & $14.5 \pm 1.4$ \\
\hline 1.0 & 121 & 20 & $2.2 \pm 0.1$ & $6.7 \pm 0.2$ & $58.1 \pm 1.3$ & $29.6 \pm 0.4$ & $11.7 \pm 0.7$ \\
\hline 1.5 & 121 & 10 & $1.0 \pm 0.2$ & $5.2 \pm 0.7$ & $54.3 \pm 2.4$ & $30.6 \pm 3.9$ & $13.2 \pm 1.4$ \\
\hline 1.5 & 121 & 15 & $4.4 \pm 0.5$ & $12.9 \pm 3.2$ & $59.2 \pm 1.4$ & $27.3 \pm 2.3$ & $12.7 \pm 3.0$ \\
\hline 1.5 & 121 & 20 & $5.7 \pm 0.3$ & $17.9 \pm 0.9$ & $64.1 \pm 1.9$ & $26.0 \pm 2.9$ & $8.8 \pm 0.7$ \\
\hline 2.0 & 121 & 10 & $3.7 \pm 0.3$ & $11.5 \pm 1.1$ & $56.5 \pm 1.1$ & $29.0 \pm 1.0$ & $13.3 \pm 1.7$ \\
\hline 2.0 & 121 & 15 & $4.1 \pm 1.0$ & $13.8 \pm 1.5$ & $59.3 \pm 2.0$ & $28.1 \pm 3.6$ & $10.8 \pm 0.9$ \\
\hline 2.0 & 121 & 20 & $8.8 \pm 2.0$ & $27.4 \pm 2.4$ & $71.9 \pm 1.1$ & $20.8 \pm 3.1$ & $7.2 \pm 1.7$ \\
\hline 2.5 & 121 & 10 & $3.1 \pm 0.2$ & $12.1 \pm 0.7$ & $61.4 \pm 2.0$ & $28.9 \pm 3.4$ & $10.5 \pm 2.1$ \\
\hline 2.5 & 121 & 15 & $11.5 \pm 0.9$ & $37.0 \pm 2.7$ & $71.4 \pm 2.0$ & $19.5 \pm 1.7$ & $7.9 \pm 2.0$ \\
\hline 2.5 & 121 & 20 & $11.3 \pm 0.5$ & $35.1 \pm 1.8$ & $76.7 \pm 1.4$ & $18.6 \pm 1.2$ & $8.1 \pm 1.1$ \\
\hline \multirow{2}{*}{$:$ Ash included } & & & & & & \\
\hline
\end{tabular}




\section{Hydrolysis of Isolated Hemicellulose- HPLC trace}

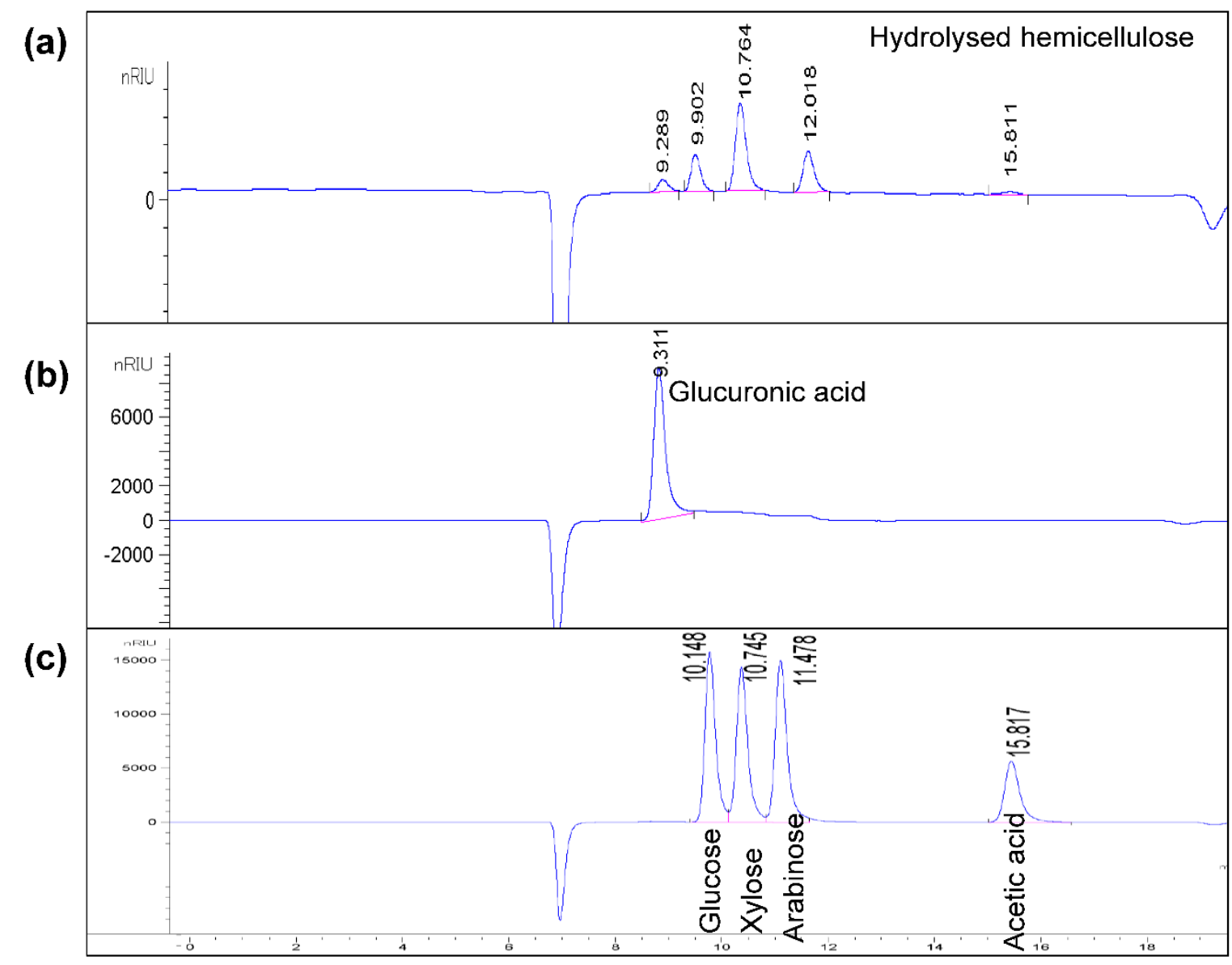

Fig. S4. HPLC chromatograms of (a) hydrolysed hemicellulose, (b) glucuronic acid and (c) glucose, xylose, arabinose, acetic acid 


\section{Xylooligosaccharides (XOS) From Isolated Hemicellulose- HPLC Trace}

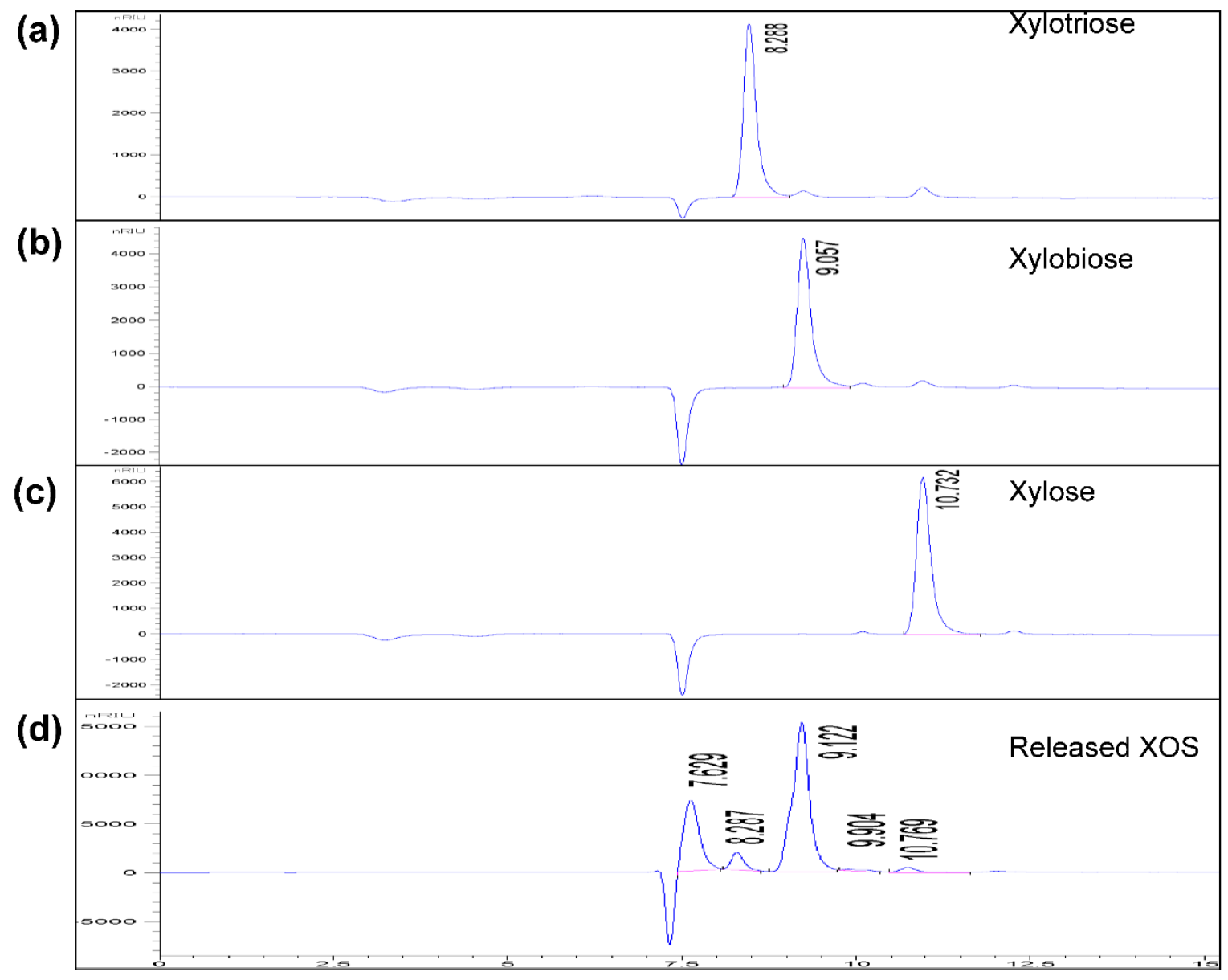

Fig. S5. HPLC chromatograms of (a) xylotriose, (b) xylobiose, (c) xylose and (d) released XOS from isolated hemicellulose 